\title{
An activity-based-parametric hybrid cost model to estimate the unit cost of a novel gas turbine component
}

\author{
Stephan Langmaak ${ }^{\mathrm{a}, 1}$, Stephen Wiseall ${ }^{\mathrm{b}, 2}$, Christophe Bru ${ }^{\mathrm{b}, 3}$, Russell Adkins ${ }^{\mathrm{c}, 4}$, James Scanlan ${ }^{\mathrm{a}, 5}$, \\ András Sóbester ${ }^{a, 6}$ \\ ${ }^{a}$ Computational Engineering and Design Research Group, University of Southampton, Southampton, SO17 1BJ, United Kingdom \\ ${ }^{\mathrm{b}}$ Rolls-Royce plc, PO Box 31, Derby, DE24 8BJ, United Kingdom \\ ${ }^{c}$ Rolls-Royce plc, Watnall Road, Hucknall, NG15 6EU, United Kingdom
}

\begin{abstract}
The first tool presented in this paper is a generic factory cost model that can estimate various costs at multiple levels of any manufacturing plant. The model is activity-based which means that the cost of each manufacturing operation is calculated and then summed up so that the true $£$-per-hour factory cost rate as well as the exact unit cost (i.e. manufacturing cost) of an unlimited number of different components can be estimated.

The second tool is a scalable cost model that estimates the unit cost of future integrally bladed disc (blisk) designs which are used by the aerospace industry in gas turbine compressors. The tool multiplies the machine cost rates, calculated by the factory cost model, by the operation times derived from blisk scaling rules. As the operation times often depend on the number of blades, the disc diameter and other design variables, many scaling rules are based on the correlation between operation times and certain design parameters. Conversely, the remaining process times are constant because they are independent of the blisk geometry. As future process times can only be estimated and the correlation between operation times and design parameters is never perfect, all operation times have uncertainty distributions. These are cascaded through the model to generate a probability distribution of the unit cost.

Through the interactive exchange of detailed cost information at the manufacturing operation level as well as extrapolated operation times, the two cost models facilitate design and manufacturing engineering to concurrently optimise blisk designs and manufacturing processes in terms of cost.
\end{abstract}

\section{Keywords}

Activity-Based Costing (ABC); Cost Estimating Relationship (CER); Factory cost modelling; Integrally bladed disk (blisk); Parametric cost modelling; Uncertainty

\footnotetext{
${ }^{1}$ Corresponding author. Tel.: +44 (0)78 00580594; Email: s.langmaak@soton.ac.uk

2 Email: steve.wiseall@rolls-royce.com

3 Email: christophe.bru@rolls-royce.com

${ }^{4}$ Email: russell.adkins@rolls-royce.com

5 Email: j.p.scanlan@soton.ac.uk

${ }^{6}$ Email: a.sobester@soton.ac.uk
} 


\section{Relevance of work}

There is limited literature on models that estimate the manufacturing cost of a design, also referred to as unit cost, using parametric process time estimation in combination with a bottom-up calculation of the resources consumed by every manufacturing process. While the bottom-up costing element of the model determines the $£$-per-hour cost rate of every manufacturing operation, the parametric tool uses the correlation between historical operation times and design data to estimate the operation times of a future product based on its design parameters. The unit cost of the new design is then predicted by multiplying the regressed operation times by the respective cost rates and adding up the resulting costs.

A similar hybrid cost model that combines bottom-up and parametric costing is described by Qian and BenArieh (2008). They estimate the machining times by multiplying the volume of material removed by the machine's material removal rate. Unfortunately, their approach is restricted to simple cylindrical parts as they depend on volumetric equations to calculate the amount of material removed. These equations would have to be changed manually in order to predict the cost of other geometries.

The scalable blisk model presented in this paper is also confined to a limited range of integrally bladed disc designs which the aerospace industry uses in gas turbine compressors. However, the model accounts for uncertainty and is based on a more complex method of manufacture where more than half of the operations are only carried out under certain design conditions. Furthermore, the number of extra features, such as holes and seals, is not restricted. The factory cost model framework itself has the flexibility to determine the costs of any factory or manufacturing cell.

\section{Introduction}

\subsection{Cost modelling}

Cost estimating is the process of predicting the cost of a work activity or output by interpreting historical data or knowledge, which is usually done by creating a cost model (Curran et al., 2004). Cost modelling, as practised in industry, is nevertheless largely based on experience rather than science, because it lacks a consolidating theory (Curran et al., 2004; Scanlan et al., 2002). Cost estimation is also information intensive, as it requires knowledge capture from various disciplines and it is affected by unpredictable factors outside design, such as inflation and market conditions (Curran et al., 2004; Scanlan et al., 2002). Unfortunately, the aerospace industry is a typical example of high-tech but low-volume manufacturing, where it is very challenging to obtain well documented and comprehensible costing information (Curran et al., 2004). Often sparse and inaccurate data increases the challenge of creating objective cost estimates and validating these (Collopy and Curran, 2005; Smith and Mason, 1997).

Parametric tools use historical data to unravel patterns and probabilistic relationships between product features and cost without having to understand the details of fabrication processes, materials and their interactions (Smith and Mason, 1997). Activity-Based Costing (ABC), on the other hand, is based on the laws of physics and fundamental manufacturing knowledge, such as production operations (Scanlan et al., 2006). Few quantitative cost models exist between the two ends of this spectrum because no suitable method has been found that can deal with multi-fidelity data from multiple levels of product definition (Scanlan et al., 2006). This project aimed to bridge the gap by making use of the synergy effects from using an $A B C$ and a parametric model in conjunction. 


\subsubsection{Costing within the aerospace industry}

In the past, aerospace product prices were simply based on cost plus profit plus contingency, as the market was not very competitive (Curran et al., 2006). The aerospace industry was therefore not forced to fully understand and reduce its cost base. Consequently, only a few cost experts dealt with cost estimation for highlevel bidding processes or detailed process-time-based models (Curran et al., 2006).

Within the last 15 years, however, market pressure from low cost airlines and reduced government defence budgets have forced aerospace companies to adapt to the conventional rule of profit which is price minus total cost (Curran et al., 2006). This, and the emergence of long-term 'power by the hour' service contracts provided by companies such as Rolls-Royce (R-R), has increased the interest of gas turbine manufacturers in reducing and controlling their manufacturing costs (Scanlan et al., 2006).

\subsection{Blisks}

Integrally bladed discs, commonly known as blisks, are currently found in axial-flow compressors of gas turbine engines. Fig. 1 shows that blisks require significantly less material because the dead weight from the blade roots, disc lugs, and the disc structure required to support these features, is no longer required. This leads to a weight saving of up to $30 \%$ (Rolls-Royce, 2005), permitting higher blade speeds and consequently higher pressure ratios per stage (Steffens, 2001). A blisk compressor therefore requires one third fewer rotor stages to achieve the same total pressure ratio as a conventional design (Steffens, 2001).

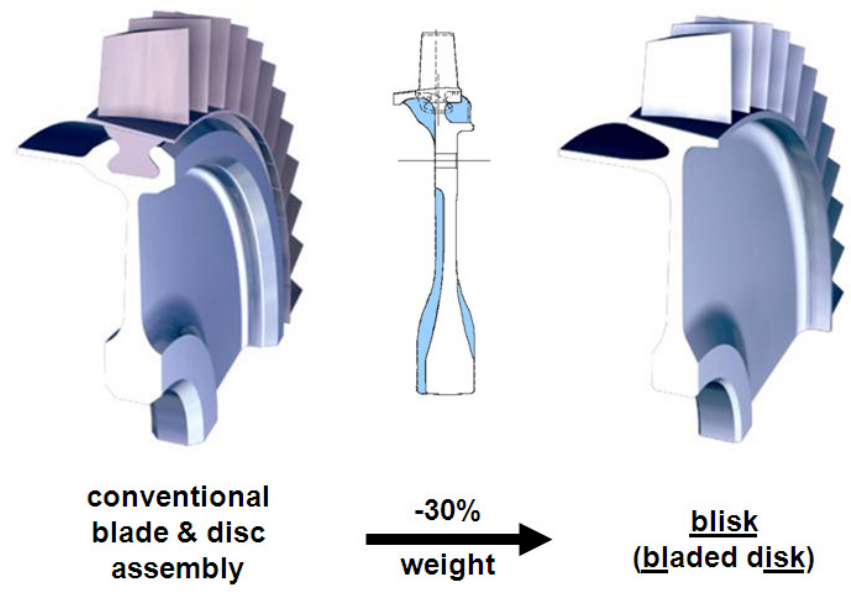

Fig. 1. Blisk weight saving.

Blisks first appeared in the 1960s in small helicopter engines and gradually grew in size and production volume (Bussmann et al., 2005; Chan, 2009; Ford et al., 2008). They are now common in military gas turbines and are starting to be included in commercial aircraft engines (Bussmann et al., 2005; Ford et al., 2008). Currently, turbine blisks are still in development because the high temperatures caused by the combusted gas can only be withstood by materials that are difficult to machine and weld (Zhan et al., 2000).

The three techniques currently used for manufacturing blisks are: Electro-Chemical Machining (ECM) for blisks with small blades, Machining From Solid (MFS) for medium sized blades and Linear Friction Welding (LFW) for large blades (Bussmann et al., 2005). Fig. 2 demonstrates where each blisk type is typically found in the compressor of a gas turbine. 


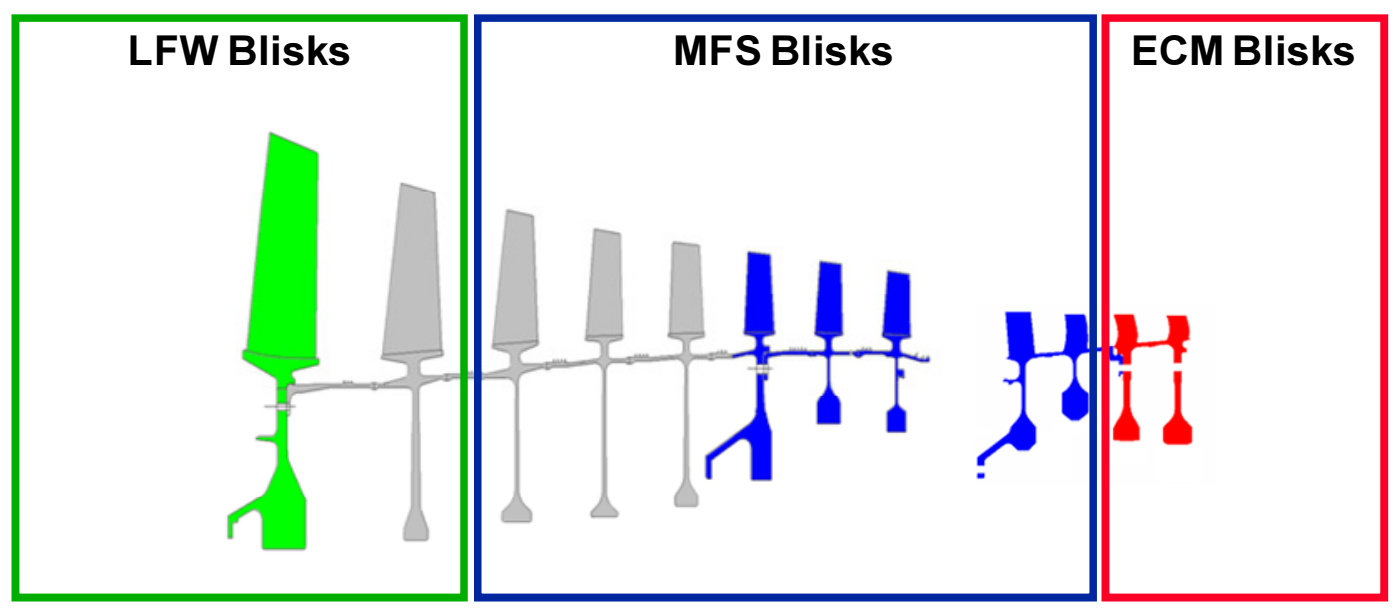

Fig. 2. Axial-flow gas turbine compressor with LFW, MFS and ECM blisks.

\subsubsection{Linear friction welding}

During the LFW process, the blade is held against the disc with an equivalent force of many tonnes while oscillating the blade on a linear path. The resulting friction causes the metal in the surrounding area to heat up until it becomes viscoplastic and is gradually squeezed out of the interface area as flash. Once the oscillation of the blade is stopped in the right location, the disc and blade material in the friction welded zone cools down to form a very high quality bond. Fig. $3 c$ illustrates the adaptive milling operation that follows the welding process to remove the flash and create the final blade foot geometry.

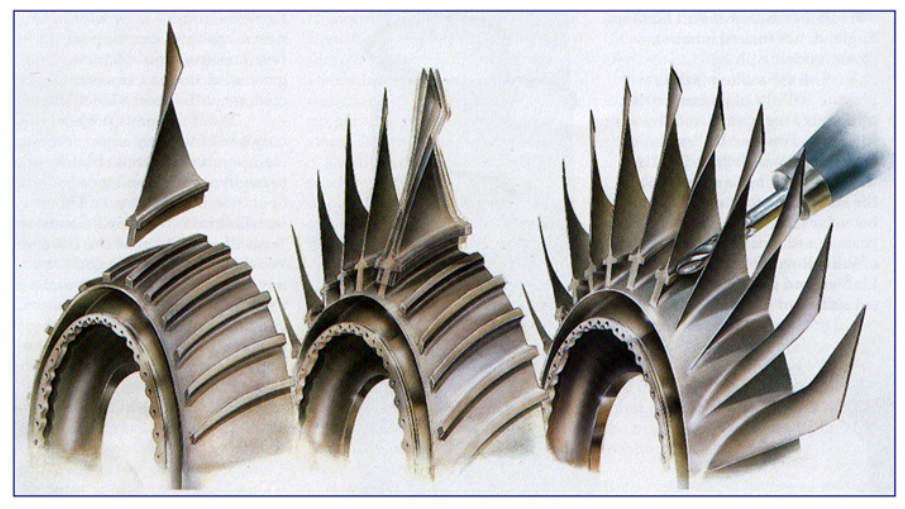

Fig. 3. (a) Disc and blade before LFW, (b) LFW process, and (c) adaptive milling.

Linear friction welding is primarily used to manufacture titanium blisks with a low blade count for the lowpressure compressor (Bussmann et al., 2005). While ECM and MFS blisks can only have solid blades, LFW also permits the use of lighter hollow blades that could be made of a different alloy to the disc (Bussmann et al., 2005; Bussmann and Bayer, 2009; Rolls-Royce, 2005). Smaller blisks are usually not linear friction welded because MFS and ECM tend to be more cost effective. The blades on smaller blisks are also more closely stacked which can make LFW impractical due to tooling access problems.

\subsubsection{Pros and cons}

In addition to weight reduction, blisks have the following advantages:

- They require less space which reduces the weight of the supporting engine structure, thus maximising the engine's power density and power-to-weight ratio (Bussmann et al., 2005; Rolls-Royce, 2005). 
- The elimination of the blade-disc joint reduces leakage flows and fatigue, the former increasing aerodynamic efficiency and stability, the latter permitting a longer service life (Bussmann et al., 2005; Kosing et al., 2001).

Blisks also have several drawbacks, however, which currently preclude their use throughout the entire compressor:

- Blisks are more expensive to manufacture because the advanced technology requires more expensive machinery, increased machining time and more elaborate quality assurance measures (Bussmann et al., 2005).

- If a blade on a blisk is badly damaged, it is likely that the entire blisk will have to be scrapped because individual blades cannot be substituted at the moment, although a blade replacement process is currently being developed (Bussmann and Bayer, 2009). Standard repairs such as blade tip blending and patching are already carried out, however (Bussmann and Bayer, 2009). The latter process involves cutting off the damaged blade area, welding on a replacement section and restoring the original contour using adaptive milling (Coppinger, 2008).

Consequently, every compressor stage in a new gas turbine requires an in-depth trade-off study between the cheaper disc and blade assembly and the lighter, more compact and more efficient blisk. This requires performance analysis tools as well as cost and weight models.

\subsection{Cost estimation of blisks}

To gain a better understanding of the trade-offs involved in blisk design, R-R needed a scalable cost model for LFW blisks to be able to quantify the impact on the blisk's unit cost caused by changing design variables, including the blisk's dimensions, the number of blades and special features such as holes and seals.

At the same time, a factory cost model was required to be able to predict the cost rate of a future LFW blisk manufacturing facility, including all the manufacturing cells within it. Such a detailed cost breakdown was needed in order to support the optimisation of the method of manufacture and the factory layout in terms of cost, quality and lead time.

While the factory cost model is covered in the next section, the scalable blisk cost model is described in more detail in Section 4. Due to confidentiality, the data presented in both the text and the figures had to be simplified, normalised or removed. All models were set up in Vanguard Studio ${ }^{\mathrm{TM}}$, a software package that, unlike a spreadsheet, generates hierarchical trees which forces the model builder to decompose a problem into a logical sequence of steps (Scanlan et al., 2006).

\section{Factory cost modelling}

Before the automation of production lines, the direct costs, including labour and material, dominated the expenses of running a factory (Curran et al., 2004; Xu, 2006). Many factory cost models therefore allocated machine depreciation and other indirect costs to a product according to the labour hours spent on the item (Curran et al., 2004; Xu, 2006).

Since the introduction of industrial robots in the 1960s, however, machine depreciation costs have increased dramatically, while labour time has decreased in relation to the total production hours (Curran et al., 2004). This means that the indirect costs, also known as factory overheads, now constitute the major part of the total production costs (Cooper and Kaplan, 1987; Curran et al., 2004; Xu, 2006). As overheads are almost 
independent of factory utilisation and therefore labour time, many companies are discovering that traditional accounting methods are too aggregated and distorted to support decision making in costing (Cooper and Kaplan, 1987; Qian and Ben-Arieh, 2008; Spedding and Sun, 1999). If production volume is used to allocate overheads for example, then high-volume products are likely to receive an excessively high fraction of the overheads and will therefore subsidise the low-volume products (Cooper and Kaplan, 1987).

\subsection{Activity-based costing}

Kaplan and Cooper consequently introduced activity-based costing in the 1980s as an alternative to the classic costing techniques (Spedding and Sun, 1999). ABC can account for indirect costs more realistically by costing the time and resources spent on each activity in the manufacture of a product (Qian and Ben-Arieh, 2008; Spedding and Sun, 1999). This means that the depreciation cost of a machine is converted into a £-perhour cost rate that is allocated to the individual products the machine processes, while the setup costs of a production batch will be distributed across the batch (Cooper and Kaplan, 1987).

Fig. 4 is a simple example of how much the unit costs of two parts, derived from an average factory cost rate for the depreciation of two machines, can diverge from the true unit costs calculated using $A B C$. The advantages of $A B C$, also known as bottom-up costing, therefore are:

- $A B C$ provides more logical, detailed and hence more comprehensive and accurate estimates of cost, especially when overhead costs are significant or when the product range is very diverse (Qian and BenArieh, 2008; Xu, 2006; Younossi et al., 2003).

- The cause and effect of every activity is understood, which allows the identification of value and non-value added manufacturing operations and how resources are consumed (Cooper and Kaplan, 1991; Curran et al., 2004; Qian and Ben-Arieh, 2008; Spedding and Sun, 1999; Xu, 2006; Younossi et al., 2003).

The drawbacks of such an in-depth breakdown of cost are:

- A significant amount of very specific and accurate data is required (Curran et al., 2004; Qian and BenArieh, 2008; Scanlan et al., 2002). This means that a detailed design definition is needed that is usually not available during the conceptual design phase (Scanlan et al., 2002).

- Developing and implementing such an accounting system is time consuming and requires expert knowledge (Curran et al., 2004).

\begin{tabular}{|c|c|c|}
\hline Description & LFW Machine & Polishing Machine \\
\hline Investment Cost (in £) & $10,000,000$ & 100,000 \\
\hline Depreciation Period (in yr) & 10 & 10 \\
\hline Part 1 Operation Time (in hr) & 5 & 10 \\
\hline Part 1 Annual Production Rate & \multicolumn{2}{|c|}{400} \\
\hline Part 2 Operation Time (in hr) & 2 & 1 \\
\hline Part 2 Annual Production Rate & \multicolumn{2}{|c|}{800} \\
\hline Machine Cost Rate (in $£ / h r$ ) & $\frac{10,000,000}{10 \times(5 \times 400+2 \times 800)}=277.78$ & $\frac{100,000}{10 \times(10 \times 400+1 \times 800)}=2.08$ \\
\hline Factory Cost Rate (in $£ / h r$ ) & \multicolumn{2}{|c|}{$\frac{10,000,000+100,000}{10 \times((5+10) \times 400+(2+1) \times 800)}=120.24$} \\
\hline Description & Part 1 & Part 2 \\
\hline $\begin{array}{l}\text { Unit Cost (in } £ \text { ) based on } \\
\text { Factory Cost Rate }\end{array}$ & $120.24 \times(5+10)=\mathbf{1 8 0 3 . 5 7}$ & $120.24 \times(2+1)=\mathbf{3 6 0 . 7 1}$ \\
\hline $\begin{array}{l}\text { Unit Cost (in £) based on } \\
\text { Machine Cost Rate, i.e. ABC }\end{array}$ & $227.78 \times 5+2.08 \times 10=\mathbf{1 4 0 9 . 7 2}$ & $277.78 \times 2+2.08 \times 1=\mathbf{5 5 7 . 6 4}$ \\
\hline $\begin{array}{l}\text { Unit Cost Error based } \\
\text { on Factory Cost Rate } \\
\text { with respect to } A B C\end{array}$ & $\frac{1803.57-1409.72}{1409.72}=\underline{\mathbf{2 7} .9 \%}$ & $\frac{360.71-557.64}{557.64}=$ \\
\hline
\end{tabular}

Fig. 4. Conventional vs. activity-based costing. 


\subsection{Model schematics}

Fig. 5 illustrates how the factory cost model replicates the structure of a real production facility by containing various manufacturing cell cost models. Machines are allocated to these cell models as indicated by the 'Fixed Costs' branch in Fig. 6. Each part type can then 'flow' through the factory according to the sequence of manufacturing operations, also known as Method of Manufacture (MoM). The 'Variable Costs' branch in Fig. 6 shows that each manufacturing operation has to be assigned to a specific machine within a specific manufacturing cell. Finally, the cell model outputs are added up in the factory cost model, together with the factory overheads and the external material costs, as illustrated in Fig. 5. In order to handle the large amount of generic input data listed in Fig. 6 efficiently, the factory cost model is based on code written in Vanguard Studio's inbuilt scripting language, DScript ${ }^{\mathrm{TM}}$, that creates the cell models and all hierarchical trees automatically.

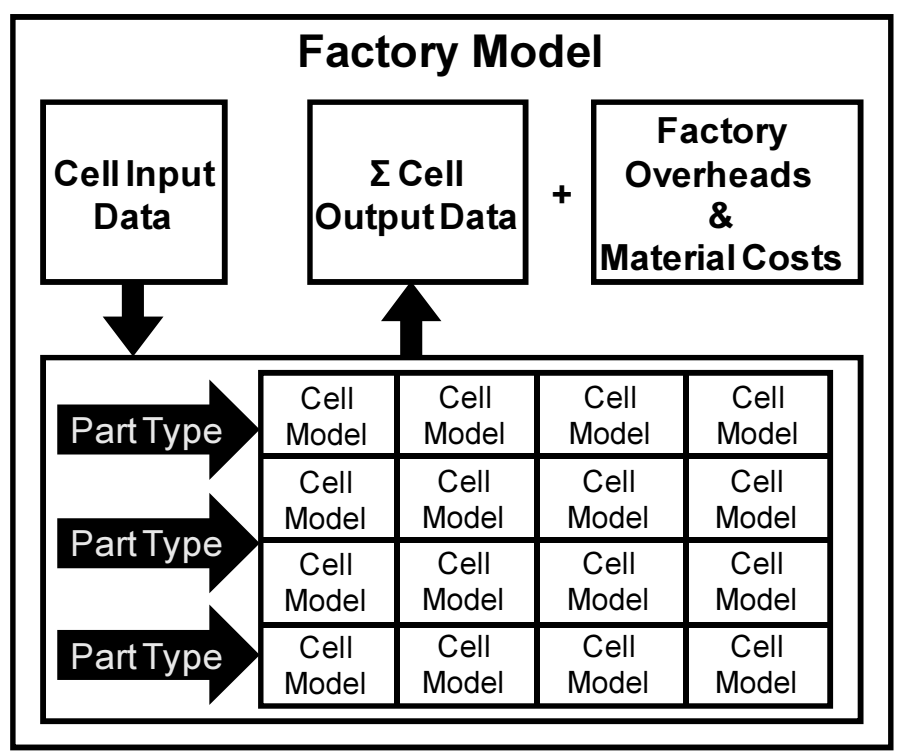

Fig. 5. Factory cost model structure. 


\begin{tabular}{|c|c|c|}
\hline $\begin{array}{l}\text { Factory Overhead Input Data: } \\
\text { Footprint Cost Rate }\left(f / y r / m^{\wedge} 2\right) \\
\text { Overhead Investment Cost }(f)\end{array}$ & $\begin{array}{l}\text { Overhead Footprint Area }\left(\mathrm{m}^{\wedge} 2\right) \\
\text { Overhead Annual Service Cost Rate ( }(/ \mathrm{yr})\end{array}$ & Overhead Depreciation Period (yr) \\
\hline
\end{tabular}

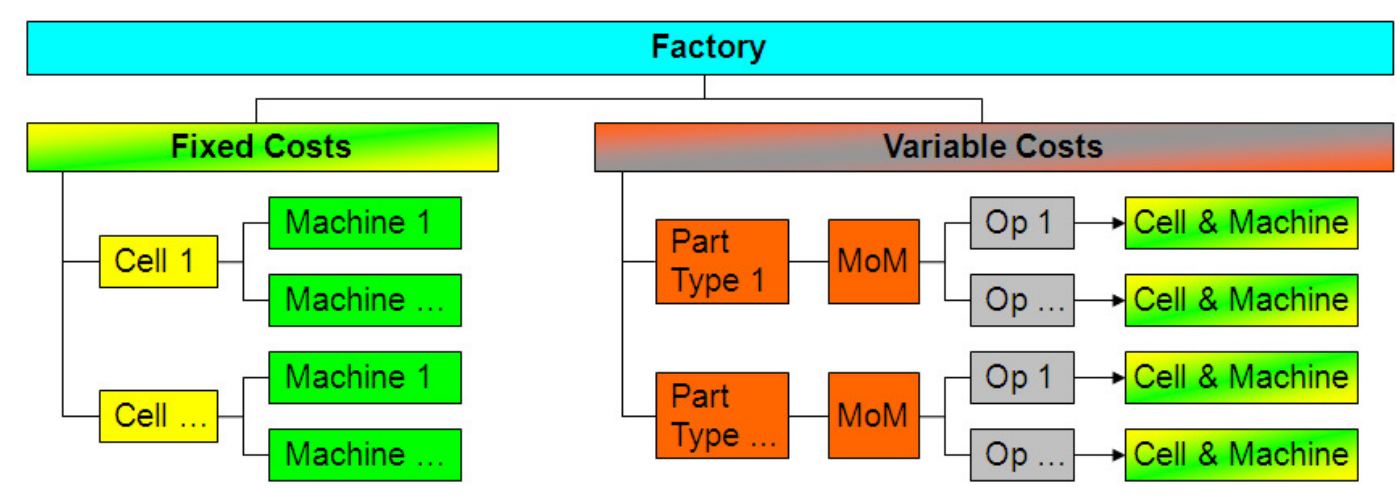

\section{Cell Input Data:}

Footprint Cost Rate $\left(£ / y r / m^{\wedge} 2\right)$

Operator Cost Rate ( $(\mathrm{h} / \mathrm{hr})$

$\mathrm{ME}^{*}$ Cost Rate $(£ / \mathrm{hr})$

Annual Working Hours per operator (hr/yr)

Annual Working Hours per ME* (hr/yr)

\begin{tabular}{|l|}
\hline Machine Input Data: \\
Machine Footprint Area $\left(\mathrm{m}^{\wedge} 2\right)$ \\
Machine Depreciation Period $(\mathrm{yr})$ \\
Machine Investment Cost $(\mathrm{f})$ \\
Machine Availability $(\mathrm{hr} / \mathrm{yr})$ \\
Machine Annual Service Cost Rate $(\mathrm{f} / \mathrm{yr})$ \\
Machine Quantity \\
Machine Capacity Limit $(\%)$
\end{tabular}

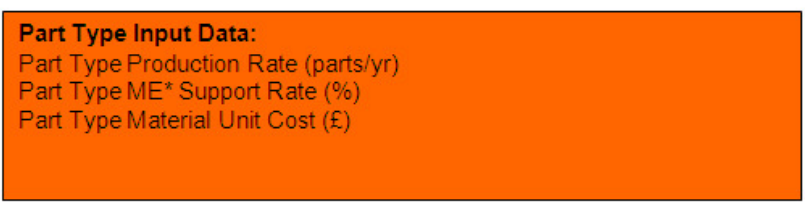

\section{Op Input Data:}

Operation Time (hr)

Operation Operator Man Hours (hr)

Operation Consumable Cost Rate $(f / \mathrm{hr})$

Operation Energy Cost Rate ( $\mathrm{f} / \mathrm{hr}$ )

Operation Scrap Cost Rate $(\mathrm{f} / \mathrm{hr})$

Operation Tooling Cost Rate $(\mathrm{f} / \mathrm{hr})$

${ }^{\text {* } M E}=$ Manufacturing Engineer

Fig. 6. Factory cost model inputs.

Fig. 7 demonstrates how the factory cost model was broken down into five levels that comply with the general rule that activities in an $A B C$ model should be separated into four categories: facility-sustaining, productsustaining, batch-level and unit-level activities (Cooper and Kaplan, 1991; Spedding and Sun, 1999; Takakuwa, 1997).

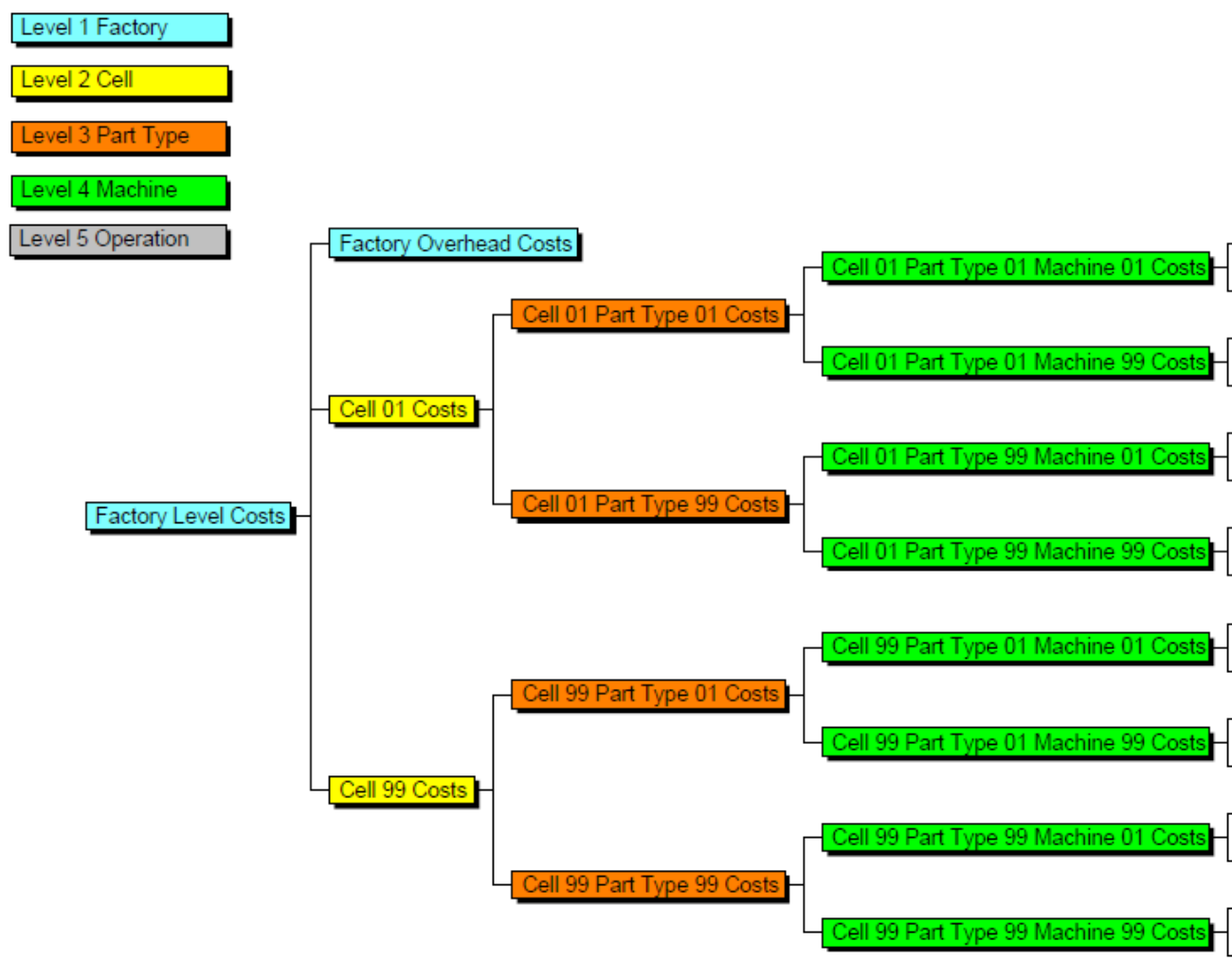

Cell 01 Part Type 01 Machine 01 Operation 01 Costs Cell 01 Part Type 01 Machine 01 Operation 99 Costs Cell 01 Part Type 01 Machine 99 Operation 01 Costs Cell 01 Part Type 01 Machine 99 Operation 99 Costs Cell 01 Part Type 99 Machine 01 Operation 01 Costs Cell 01 Part Type 99 Machine 01 Operation 99 Costs Cell 01 Part Type 99 Machine 99 Operation 01 Costs Cell 01 Part Type 99 Machine 99 Operation 99 Costs Cell 99 Part Type 01 Machine 01 Operation 01 Costs Cell 99 Part Type 01 Machine 01 Operation 99 Costs Cell 99 Part Type 01 Machine 99 Operation 01 Costs Cell 99 Part Type 01 Machine 99 Operation 99 Costs Cell 99 Part Type 99 Machine 01 Operation 01 Costs Cell 99 Part Type 99 Machine 01 Operation 99 Costs Cell 99 Part Type 99 Machine 99 Operation 01 Costs Cell 99 Part Type 99 Machine 99 Operation 99 Costs

Fig. 7. Factory cost model hierarchy. 
The factory cost model's tree structure does not include a batch level, however, because the bulkiness of LFW blisks and their low production volumes make automatic batch setup and handling ineffective. Consequently, batch size does not have a significant effect on the machine setup times and costs of LFW blisks.

\section{Scalable blisk cost model}

Fig. 8 represents the interaction between the activity-based factory cost model and the parametric scalable blisk cost model. The main purpose of the scalable cost model is to estimate the operation times required to manufacture a future blisk, based on design parameters that drive the operation times and hence cost. These times are then passed to the factory cost model together with the planned production volume, in order to calculate the machine cost rates and the other outputs mentioned in Fig. 8. The machine cost rates can then be fed back into the scalable model in order to generate uncertainty distributions of the blisk unit cost. The details of how the operation times and the uncertainty distributions are generated are discussed in the following sub-sections.

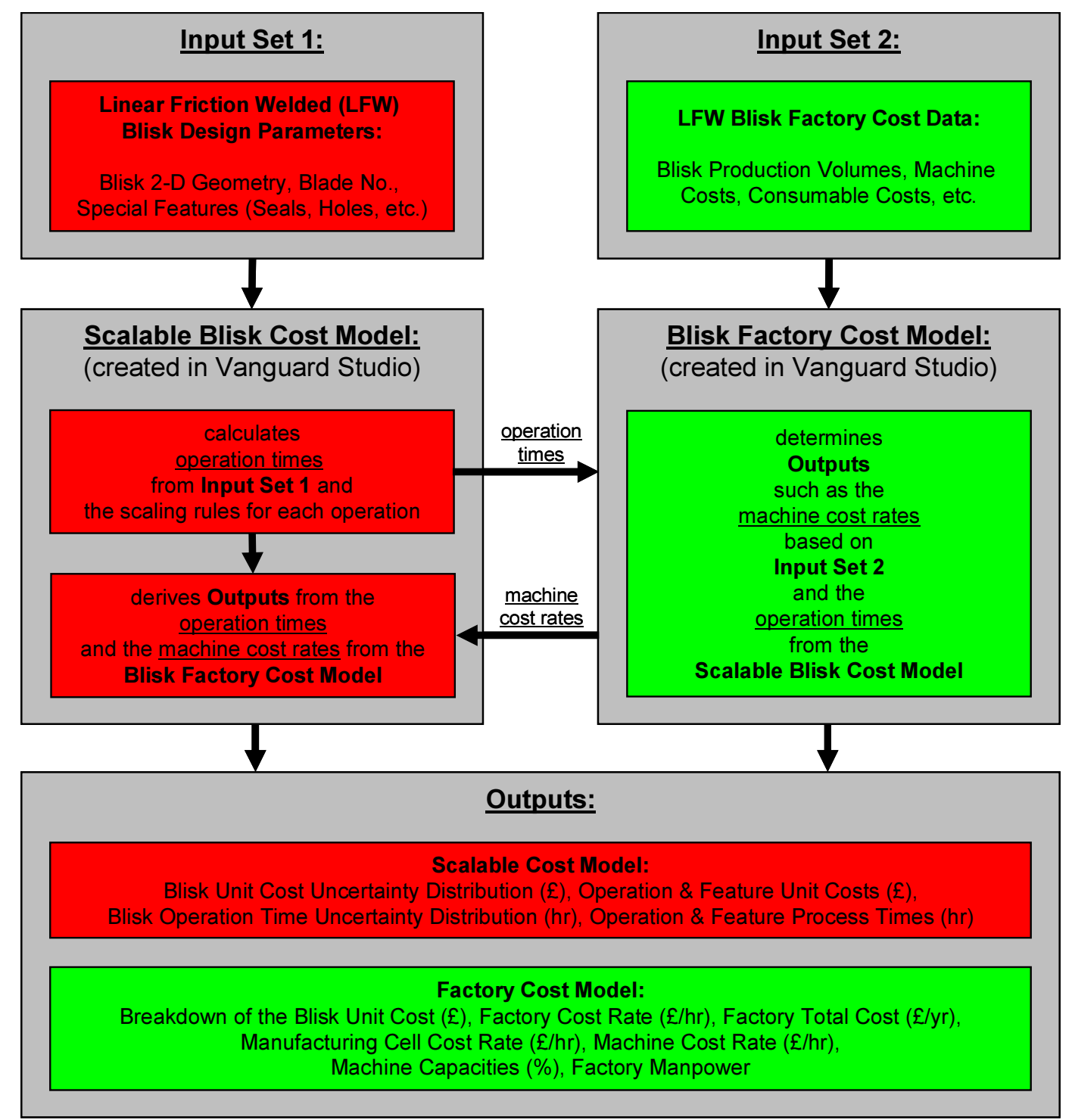

Fig. 8. Scalable blisk and factory cost model interaction.

\subsection{Blisk design variability}

Each LFW blisk has a highly unique design with several hundred features and many thousand measured points. Consequently, the method of manufacture and the duration of its operations vary significantly. The unit 
cost of a LFW blisk with hollow blades and a disc with many complex features can cost several times more in a full-production environment than a simpler LFW blisk with solid blades.

The scalable cost model therefore had to be able to automatically modify the MoM and the operation times based on the design inputs. An additional challenge arose as the authors only had access to sparse and inaccurate data of five pre-production blisk designs.

\subsection{Model structure}

The disguised MoM in Fig. 9 reflects the uniqueness of each blisk design considering that only 28 operations are common to each blisk, while the remaining 37 operations only apply under certain conditions. Only 53 of the total 65 operations and sub-operations are unique, however, because several operations in the method appear more than once. Rather than modelling the complex machining and inspection operations in their entirety, they were broken down into the 14 sub-operations shown in the top right table in Fig. 9, including rough turning, finish turning, hole machining and tight tolerance inspection for example.

\begin{tabular}{|c|c|c|}
\hline $\begin{array}{l}\mathrm{OP} \\
\text { No. }\end{array}$ & $\begin{array}{c}\text { Manufacturing } \\
\text { Operation }\end{array}$ & $\begin{array}{l}\text { Applies } \\
\text { When }\end{array}$ \\
\hline 10 & MISCELLANEOUS (C1) & always \\
\hline 20 & OUTSOURCED (L1) & always \\
\hline 30 & MISCELLANEOUS (L2) & always \\
\hline 40 & $\begin{array}{l}\text { SURFACE TREATMENT } \\
\text { (C2) }\end{array}$ & always \\
\hline 50 & INSPECTION (R1) & always \\
\hline 60 & OUTSOURCED (C3) & always \\
\hline 70 & $\begin{array}{l}\text { SURFACE TREATMENT } \\
\text { (C4) }\end{array}$ & always \\
\hline 80 & $\begin{array}{l}\text { SURFACE TREATMENT } \\
\text { (C5) }\end{array}$ & always \\
\hline 90 & MACHINING (S1) & $\begin{array}{c}\text { see } \\
\text { sub-operations }\end{array}$ \\
\hline 100 & $\begin{array}{l}\text { SURFACE TREATMENT } \\
\text { (C5) }\end{array}$ & optional \\
\hline 110 & $\begin{array}{l}\text { SURFACE TREATMENT } \\
\text { (C5) }\end{array}$ & optional \\
\hline 120 & MACHINING (S1) & $\begin{array}{c}\text { see } \\
\text { sub-operations }\end{array}$ \\
\hline 130 & MACHINING (S1) & $\begin{array}{c}\text { see } \\
\text { sub-operations }\end{array}$ \\
\hline 140 & $\begin{array}{l}\text { SURFACE TREATMENT } \\
\text { (C6) }\end{array}$ & always \\
\hline 150 & MACHINING (R2) & always \\
\hline 160 & INSPECTION (R3) & always \\
\hline 170 & $\begin{array}{l}\text { SURFACE TREATMENT } \\
(\mathrm{C} 2)\end{array}$ & optional \\
\hline 180 & OUTSOURCED (L3) & optional \\
\hline 190 & MACHINING (S1) & $\begin{array}{c}\text { see } \\
\text { sub-operations }\end{array}$ \\
\hline 200 & $\begin{array}{l}\text { SURFACE TREATMENT } \\
\text { (C5) }\end{array}$ & always \\
\hline 210 & $\begin{array}{l}\text { SURFACE TREATMENT } \\
\text { (C5) }\end{array}$ & always \\
\hline 220 & MACHINING (S1) & $\begin{array}{c}\text { see } \\
\text { sub-operations }\end{array}$ \\
\hline 230 & MACHINING (S1) & $\begin{array}{c}\text { see } \\
\text { sub-operations }\end{array}$ \\
\hline 240 & $\begin{array}{l}\text { SURFACE TREATMENT } \\
\text { (C5) }\end{array}$ & always \\
\hline 250 & MACHINING (L4) & optional \\
\hline 260 & MACHINING (S1) & $\begin{array}{c}\text { see } \\
\text { sub-operations }\end{array}$ \\
\hline 270 & $\begin{array}{l}\text { SURFACE TREATMENT } \\
\text { (C5) }\end{array}$ & optional \\
\hline 280 & $\begin{array}{l}\text { SURFACE TREATMENT } \\
(\mathrm{R} 4)\end{array}$ & always \\
\hline 290 & INSPECTION (C7) & optional \\
\hline 300 & INSPECTION (R5) & always \\
\hline 310 & $\begin{array}{l}\text { SURFACE TREATMENT } \\
(\mathrm{C} 8)\end{array}$ & always \\
\hline
\end{tabular}

\begin{tabular}{|c|c|c|}
\hline $\begin{array}{l}\mathrm{OP} \\
\text { No. }\end{array}$ & $\begin{array}{c}\text { Manufacturing } \\
\text { Operation }\end{array}$ & $\begin{array}{c}\text { Applies } \\
\text { When }\end{array}$ \\
\hline 320 & INSPECTION (L5) & optional \\
\hline 330 & INSPECTION (C9) & always \\
\hline 340 & $\begin{array}{l}\text { SURFACE TREATMENT } \\
\text { (C10) }\end{array}$ & always \\
\hline 350 & INSPECTION (C11) & always \\
\hline 360 & $\begin{array}{l}\text { SURFACE TREATMENT } \\
\text { (C12) }\end{array}$ & optional \\
\hline 370 & INSPECTION (C13) & optional \\
\hline 380 & OUTSOURCED (R6) & optional \\
\hline 390 & $\begin{array}{l}\text { SURFACE TREATMENT } \\
\text { (C14) }\end{array}$ & optional \\
\hline 400 & $\begin{array}{l}\text { SURFACE TREATMENT } \\
\text { (C15) } \\
\end{array}$ & always \\
\hline 410 & $\begin{array}{l}\text { SURFACE TREATMENT } \\
\text { (C5) }\end{array}$ & optional \\
\hline 420 & MACHINING (S1) & $\begin{array}{c}\text { see } \\
\text { sub-operations } \\
\end{array}$ \\
\hline 430 & MACHINING (S1) & $\begin{array}{c}\text { see } \\
\text { sub-operations }\end{array}$ \\
\hline 440 & $\begin{array}{l}\text { SURFACE TREATMENT } \\
\text { (C5) }\end{array}$ & always \\
\hline 450 & MACHINING (R7) & always \\
\hline 460 & $\begin{array}{l}\text { SURFACE TREATMENT } \\
\text { (C16) }\end{array}$ & optional \\
\hline 470 & $\begin{array}{l}\text { SURFACE TREATMENT } \\
\text { (R8) }\end{array}$ & optional \\
\hline 480 & INSPECTION (C17) & optional \\
\hline 490 & INSPECTION (C18) & optional \\
\hline 500 & INSPECTION (C19) & optional \\
\hline 510 & INSPECTION (C19) & optional \\
\hline 520 & MACHINING (C20) & optional \\
\hline 530 & $\begin{array}{l}\text { SURFACE TREATMENT } \\
\text { (C21) }\end{array}$ & optional \\
\hline 540 & INSPECTION (C11) & optional \\
\hline 550 & INSPECTION (C7) & always \\
\hline 560 & INSPECTION (R9) & optional \\
\hline 570 & INSPECTION (R10) & optional \\
\hline 580 & INSPECTION (S2) & $\begin{array}{c}\text { see } \\
\text { sub-operations }\end{array}$ \\
\hline 590 & $\begin{array}{l}\text { SURFACE TREATMENT } \\
\text { (C22) }\end{array}$ & always \\
\hline 600 & INSPECTION (R11) & always \\
\hline 610 & MISCELLANEOUS (C23) & optional \\
\hline
\end{tabular}

\begin{tabular}{|c|c|c|c|}
\hline $\begin{array}{c}\text { Manufacturing } \\
\text { Operation }\end{array}$ & $\begin{array}{l}\text { OP } \\
\text { No. }\end{array}$ & $\begin{array}{l}\text { Manufacturing } \\
\text { Sub-Operation }\end{array}$ & $\begin{array}{l}\text { Applies } \\
\text { When }\end{array}$ \\
\hline \multirow{12}{*}{$\begin{array}{c}\text { MACHINING } \\
\text { (S1) }\end{array}$} & 620 & MACHINING (R12) & optional \\
\hline & 630 & MACHINING (R13) & optional \\
\hline & 640 & MACHINING (R14) & always \\
\hline & 650 & MACHINING (R15) & always \\
\hline & 660 & MACHINING (L6) & optional \\
\hline & 670 & MACHINING (L7) & optional \\
\hline & 680 & MACHINING (L8) & optional \\
\hline & 690 & MACHINING (L9) & optional \\
\hline & 700 & MACHINING (L10) & optional \\
\hline & 710 & MACHINING (L11) & optional \\
\hline & 720 & MACHINING (L12) & optional \\
\hline & 730 & MACHINING (L13) & optional \\
\hline \multirow{2}{*}{$\begin{array}{l}\text { INSPECTION } \\
\text { (S2) }\end{array}$} & 740 & INSPECTION (C24) & optional \\
\hline & 750 & INSPECTION (C25) & optional \\
\hline
\end{tabular}

Fig. 9. Scaling rules for the generic LFW method of manufacture. 
For the 15 processes identified as R1 to R15 in Fig. 9, linear regression analysis was used to determine an approximate relationship between the varying operation times and the design parameters because simple and intuitive scaling rules, such as material volume removed multiplied by the material removal rate, could not capture the complexity of these operations. While the regression analysis methodology is described in more detail in the next sub-section, the Gaussian uncertainty distribution that was applied to these 15 scaling rules is covered in Section 4.4.3.

While regression or intuitive linear relationships were used to derive the scaling rules for operations $L 1$ to $L 13$, $\mathrm{C} 1$ to $\mathrm{C} 25$ have constant times. As the manufacturing engineers estimated the error bounds of the scaling rules for $L 1$ to $L 13$ and $C 1$ to $C 25$, the predicted operation times have triangular uncertainty distributions, which are further discussed in Section 4.4.2.

When the scalable blisk cost model is run, the input windows illustrated in Fig. 10a-d are successively presented to the user. The blade, disc and blisk input screens list both the design parameters required to drive the scaling rules and the conditions that determine which optional operations apply. Instead of specifying the values of the parameters listed in Fig. 10b-d every time the model is run, the values of an unlimited number of blisks can be stored in a table within the model. By typing the name of the blisk into Fig. 10a, the relevant data can then be loaded when required. 
The estimated ADAPTIVE MILLING TIME and BLADE FOOT CMM TIME are $7 \%$ below the dataset range the model is based on.

If possible, please increase the BLADE NUMBER by least

4, the BLADE ROOT STAGGER ANGLE RATE by at least 0.022 $\mathrm{deg} / \mathrm{mm}$ of the BLADE ROOT CHORD LENGTH by at least $7 \mathrm{~mm}$ (or a combination of the three).

a) Optional Loading of Blisk Data

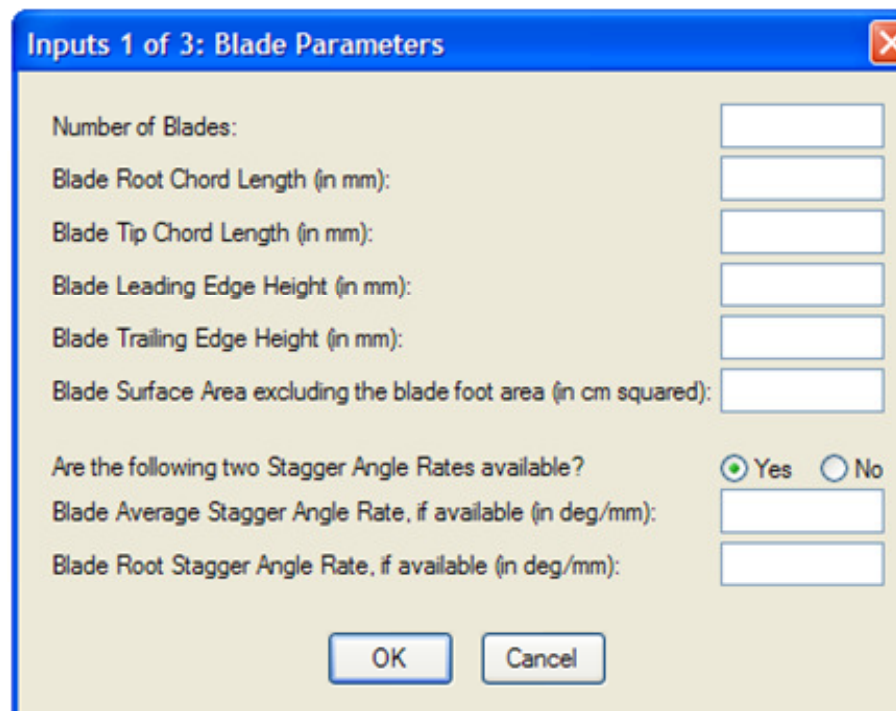

b) Blisk Blade Parameters

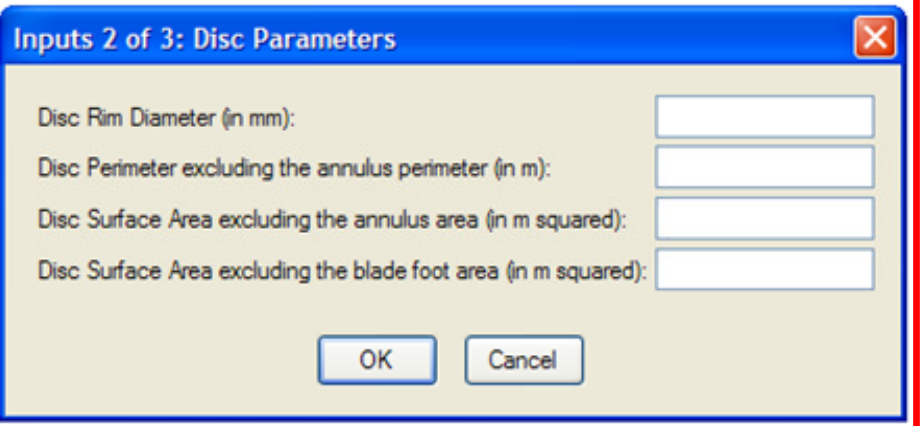

\section{c) Blisk Disc Parameters}

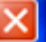

e) Extrapolation Warning

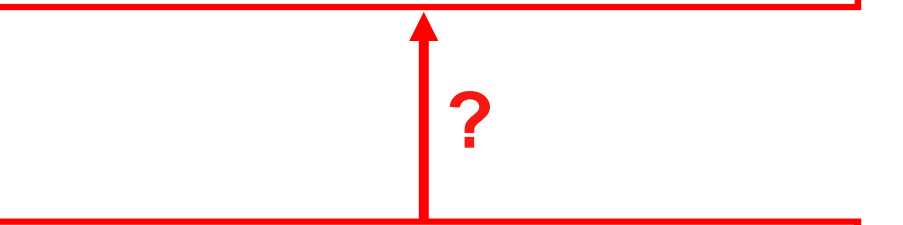

Inputs 3 of 3 : Blisk Parameters

\begin{tabular}{|c|c|}
\hline Is a signficant amount of Rough Tuming required? & OYes \\
\hline Is blisk a Miltary or Civil project? & Miltary \\
\hline Is blisk Bolted or Welded onto other rotors? & Bolted \\
\hline Is blisk Balanced? & OYes \\
\hline Is blisk Balance Corrected? & ○Yes \\
\hline Are Shank Nuts fitted onto blisk? & OYes \\
\hline Blisk Complexity: & Low \\
\hline
\end{tabular}

Number of Non-Angled Holes ( $<=10 \mathrm{~mm}$ diameter):

Number of Non-Angled Holes ( $\$ 10 \mathrm{~mm}$ diameter):

Number of Angled Holes:

Number of Balance Hooks with scallops:

Number of Scallops with holes:

Number of Seals:

Number of Slots:

Number of Spline Teeth:

Tight Tolerance Surface Area (in cm squared):

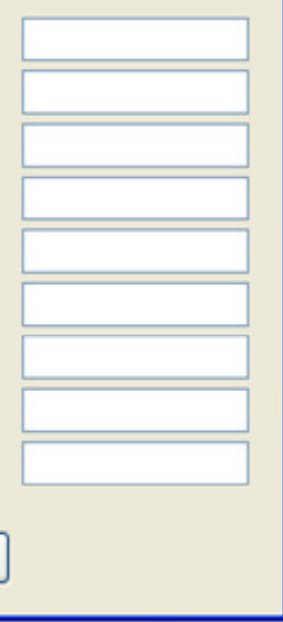

\section{d) Blisk Parameters}

Fig. 10. Scalable blisk cost model user interface. (a) Optional loading of blisk data, (b) blisk blade parameters, (c) blisk disc parameters, (d) blisk parameters, and (e) extrapolation warning.

A common pitfall with regression that can lead to an incorrect cost forecast is to predict outside the existing data range or to apply it to a new technology that is radically different from those the relationship is based on (Curran et al., 2004; Younossi et al., 2003). If the user therefore chooses design parameter settings that lead to an extrapolation beyond the dataset that define the scaling rules, then one or more warning messages will appear, such as the example in Fig. 10e.

Many of the design parameters, including the blade surface area and the disc perimeter, can only be obtained from Computer Aided Design (CAD) models. As these are usually not available at the preliminary design stage, the user has the option of using a Microsoft Excel ${ }^{\circledR}$ interface that approximates the blade surface area and the disc perimeter using a simplistic cross-sectional blisk model defined by 24 grid points, the number of blades and the blade root stagger angle, i.e. the angle between the chord line at the blade root and the blisk's axis of 
rotation. As special features, such as the number of holes and seals, might also be unknown during the conceptual design phase, the user could apply uncertainty distributions to those inputs in addition to the ones that already exist for the scaling rules.

Due to time constraints and limited access to data, the scalable blisk cost model does not account for the disc and blade manufacturing costs. It is critical that these costs are eventually included in the model considering that they account for approximately half of the total unit costs of a solid-bladed blisk and significantly more of a blisk with hollow blades.

\subsection{Regression analysis}

\subsubsection{Cost estimating relationship}

A parametric Cost Estimating Relationship (CER) establishes a relationship between cost and one or more input parameters that affect cost, often defined using a regression model based on historical data (Curran et al., 2005; Curran et al., 2004; Qian and Ben-Arieh, 2008; Younossi et al., 2003). The following criteria are important in selecting the right cost drivers:

- They have to be statistically independent of one another and logically related to cost (Birkler et al., 1982; Curran et al., 2004).

- The parameters have to be known with a reasonable level of confidence at whatever stage of the product's lifecycle a cost estimate is needed (Birkler et al., 1982; Curran et al., 2004).

- Only those variables that best explain cost should be selected to minimise correlation effects and reduce the impact of the cumulative ambiguity of these parameters on the uncertainty of the cost prediction (Birkler et al., 1982; Younossi et al., 2003).

Parametric models are generally better suited to estimate recurring costs, i.e. unit costs, than non-recurring research and development costs because the former are less sensitive to programme peculiarities (Dryden and Large, 1977).

\subsubsection{Advantages}

Parametric cost estimation was first used by the U.S. government during the Second World War to quickly agree on unit prices for military aircraft based on their weight (Kwak and Watson, 2005; Scanlan et al., 2006). Since then, associative cost models have become very common within aerospace because they require few inputs to achieve reasonable accuracy (Birkler et al., 1982). The advent of statistical methods, such as regression, have contributed to the popularity of the CER because regression analysis also allows the statistical accuracy of the correlation between cost and the cost-driving parameters to be determined (Curran et al., 2004). Regression therefore enables the cost model to be used as both an analytical and a predictive tool (Kim et al., 2004), and can also highlight data outliers which is ideal for validating scaling rules and the underlying data (Finnie et al., 1997).

While the $A B C$ approach requires detailed knowledge of the manufacturing processes involved, this is not the case for parametric cost models (Birkler et al., 1982). The latter treats historical costs as facts and the manufacturing detail that generates the costs does not have to be considered (Collopy and Curran, 2005; Scanlan et al., 2002). Other advantages are that CERs are quick and easy to implement and that nontechnical experts can apply the method, even during the early stages of design when resources are limited (Birkler et al., 1982; Curran et al., 2004; Qian and Ben-Arieh, 2008; Younossi et al., 2003). In addition, 
parametric cost models allow the inclusion of cost as a variable in system design tools and also enable the uncertainty of the predictions to be quantified (Bearden, 2001; Curran et al., 2004; Muia et al., 2009; Younossi et al., 2003).

\subsubsection{Resolving the disadvantages}

A major drawback of the CER is that historical cost data has to be carefully normalised to eliminate the effects of inflation, exchange rates, technology levels, market forces, production volumes and varying manufacturing performance (Curran et al., 2005; Curran et al., 2004; Scanlan et al., 2002; Younossi et al., 2003). As the scalable blisk cost model is based on the data from a single generation of one component family where only the design of each blisk differs, the data did not have to be normalised. The cost of a new LFW blisk design can be predicted without having to alter the scaling rules as long as it belongs to the same generation, i.e. is made of the same material and does not require different manufacturing processes. Any changes in the machine cost rates due to inflation, capacity adjustments in existing production lines or the creation of a new factory can be accounted for by modifying the factory cost model accordingly.

If a CER is required for design optimisation, then one has to ensure that the design parameters are causally related to cost and not just correlated (Collopy and Eames, 2001; Younossi et al., 2003). As there is no need to model individual manufacturing activities and justify cost variability, there is a significantly higher risk that parametric methods do not identify the true cause-and-effect relationships of cost, unlike ABC (Curran et al., 2004; Qian and Ben-Arieh, 2008; Younossi et al., 2003). It was therefore decided to make the scalable cost model an activity-based-parametric hybrid that combines the simplicity of the CER with the accuracy of estimating costs at the activity level.

Several sources (Finnie et al., 1997; Scanlan et al., 2002; Smith and Mason, 1997) state that regression models normally require a relatively large dataset in order to identify statistically meaningful relationships. Other parametric techniques, such as artificial neural networks, also require a significant amount of data, however (Curran et al., 2004). As this project suffers from a lack of data to validate the scaling rules, the inherent uncertainty is built into the model which is discussed in more detail in Section 4.4. Although Kim et al. (2004) state that regression analysis cannot be applied to non-linear relationships and multiple outputs, the next sub-section explains why this project is not affected by these restrictions.

\subsubsection{Application}

The blisk design variables that affect the operation times, and hence the unit cost, were identified by questioning R-R manufacturing engineers. A trial and error approach was then used to find the combination of design parameters that best explained the variability in the operation times. In order to predict the inspection operation time of a future blisk using the scaling rule shown in Fig. 11 for example, the Blade Parameter 1 and Blade Parameter 2 values of that blisk simply have to be inserted into the regression line equation shown in Fig. 11.

While the coefficient of determination, $R^{2}$, measures how well the regression line describes the variability in the data, the p-value is the probability that the variability is better explained by chance rather than by the regression model. In order to be a good fit, the $R^{2}$ value should be close to $100 \%$ and the p-value below $5 \%$ (Stat-Ease, 2010). One of the best fits found is displayed in Fig. 11, which has a $R^{2}$ value of $99.2 \%$ and a pvalue of $0.03 \%$. Here, the data points of the five blisks lie very close to the regression line. The fitted line in Fig. 
12 , on the other hand, only has a $R^{2}$ value of $62.1 \%$ and a $p$-value of $11.3 \%$ because the five data points are scattered far from the regression line. This is the most inaccurate scaling rule in the model, not only because it is a bad fit but also because it accounts for a significant proportion of the total manufacturing operation time of a blisk.

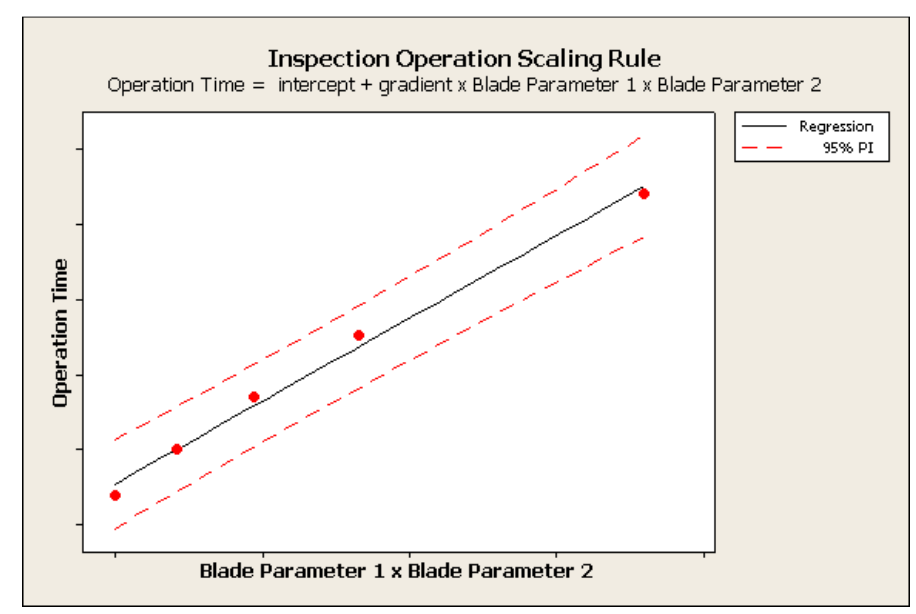

Fig. 11. A scaling rule with a good fit.

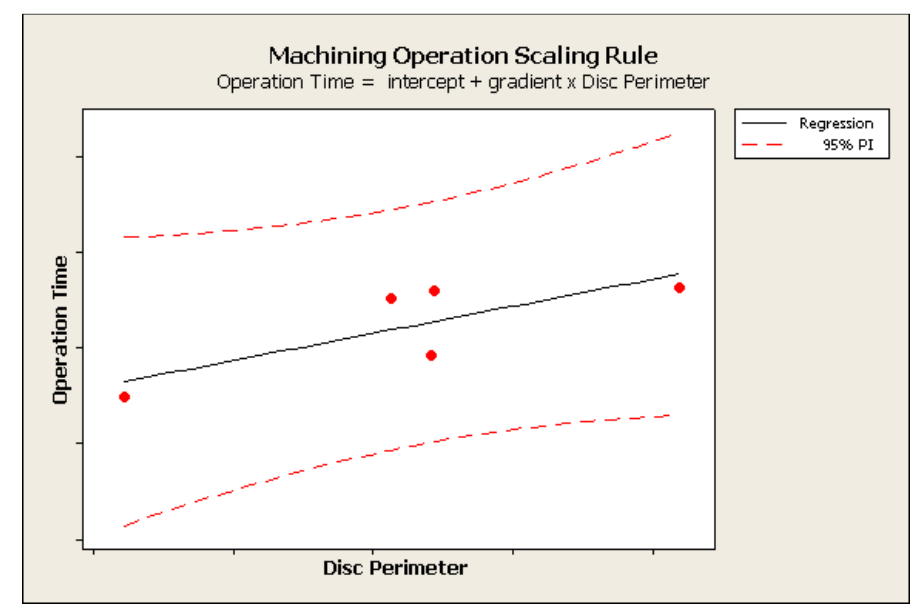

Fig. 12. A scaling rule with a bad fit.

\subsection{Uncertainty}

\subsubsection{Background}

Although more complicated to implement, estimate ranges have the following advantages in comparison to single point predictions:

- They are more realistic because mathematical theory states that the summation of 'most likely' point estimates tends to underestimate costs by a large margin (Book, 2001).

- The sensitivity of product costs to manufacturing process variability and other uncertainties can be determined (Von Beck and Nowak, 2000).

- Single point estimates ignore the fact that cost drivers are often correlated which increases the cost uncertainty (Book, 2001).

Knowing the probability distribution of cost can help to mitigate the risk of a project if the variability is addressed through avoidance, adjustment and contingency (Curran et al., 2004). By not only comparing and 
optimising product designs in terms of their expected cost but also their cost uncertainty, robust designs can be formed (Curran et al., 2004).

Monte Carlo Simulation is a simple and widely used method for cascading uncertainty through a computer model. In cost models, one application of Monte Carlo Simulation is to determine the impact of design parameter variability on the product's cost uncertainty. The Monte Carlo Simulation Add-In for Vanguard Studio (Vanguard, 2010) can model various input uncertainty distributions to generate the Gaussian-type Probability Density Function (PDF) and the S-shaped Cumulative Distribution Function (CDF) in both Figs. 14 and 15. While the PDF shows the relative likelihood of meeting a specific cost target, the CDF accrues the probabilities of all costs less or equal to the target value. Being able to predict costs at the $50 \%, 70 \%$ or $85 \%$ confidence level are much more valuable to decision makers than 'most likely' estimates (Book, 2001). Vanguard Studio's Monte Carlo simulation package therefore enables cost model builders to meet the requirement of providing a cost prediction together with its associated probability of occurrence (Curran et al., 2004).

\subsubsection{Triangular uncertainty distribution}

In addition to the expected blisk operation times, their uncertainty ranges were collected because the predictability of the operation times varied significantly, depending on the maturity of each process. Accounting for the uncertainty also ensured that the manufacturing engineers agreed to formally sign off the scaling rules created. The scaling rules with triangular uncertainty distributions are simply described by a maximum, a most likely and a minimum operation time that define the shape of the triangle displayed in Fig. 13.

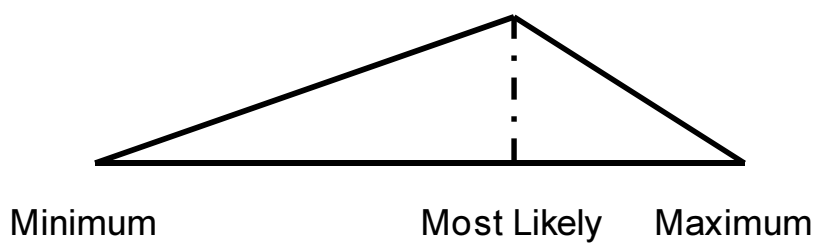

Fig. 13. Triangular distribution.

\subsubsection{Prediction interval}

The scaling rules for operations R1 to R15 in Fig. 9 have Gaussian uncertainty distributions which are based on the prediction intervals derived from the regression analysis described in Section 4.3.4. The prediction interval represents the range in which a single new prediction is likely to fall, usually with $95 \%$ confidence (Minitab, 2007). This analytical method is statistically more accurate than the subjective triangular distribution because, according to Montgomery and Runger (2003), it is a reasonable assumption that even for a small sample size the underlying distribution is normal, i.e. Gaussian. The prediction interval also takes the fit of the regression line into account as well as the number of data points (Curran et al., 2004). Unlike the triangular distributions provided by the manufacturing engineers, the prediction intervals cannot take the uncertainty in the underlying data into account, however. Nonetheless, the scaling rules for R1 to R15 are based on the prediction intervals because they produced greater and therefore more conservative uncertainty ranges than the triangular distributions.

The dashed lines in Figs. 11 and 12 indicate the outer boundaries of the 95\% confidence Prediction Interval $(\mathrm{PI})$. They illustrate how significant the impact of the goodness of the regression line fit is on the prediction 
interval. While the limits of the prediction interval in Fig. 11 only deviate from the mean by 5 to $10 \%$, it is around 100 to $200 \%$ in Fig. 12. The lower prediction interval limit in Fig. 12 was not capped at zero, even though it extends into negative operation time, in order not to falsify the unit cost distribution.

The prediction interval is based on the t-distribution, which is identical to the normal distribution when the number of data samples, $k$, is infinite. If only a finite number of data points is available, however, the tails of the t-distribution become larger, which increases the prediction interval.

Eq. (1), adapted from Montgomery and Runger (2003), shows how the prediction interval limits, $Y$, of the dependent variable, $y$, are calculated based on the value of the independent variable, $x$.

$$
Y=\hat{y} \pm t_{\alpha / 2, v} \sqrt{\hat{\sigma}^{2}\left[1+\frac{1}{n}+\frac{(x-\bar{x})^{2}}{S_{x x}}\right]} \quad \text { where } \quad \begin{aligned}
& \hat{y}=\hat{\beta}_{0}+\hat{\beta}_{1} x \\
& v=n-2 \\
& \hat{\sigma}^{2}=\frac{\sum_{i=1}^{n}\left(y_{i}-\hat{y}_{i}\right)^{2}}{v} \\
& S_{x x}=\sum_{i=1}^{n}\left(x_{i}-\bar{x}\right)^{2}
\end{aligned}
$$

here:

- $\quad \hat{y}$ is the value of the regression model's dependent variable

- $t_{\alpha / 2, v}$ is the percentage point of the t-distribution based on a confidence limit of $\alpha$ and $v$ degrees of freedom

- $\hat{\sigma}$ is the standard deviation of the data points with respect to the regression model

- $\bar{x}$ is the mean value of the independent variable of the $n$ data points

- $S_{x x}$ is the sum of squares of the independent variable $x$ of the $n$ data points

- $\hat{\beta}_{0}$ is the intercept of the regression line

- $\hat{\beta}_{1}$ is the slope of the regression line

- $y_{i}$ is the value of the dependent variable of the $i^{\text {th }}$ data point and $\hat{y}_{i}$ is its regressed value

- $x_{i}$ is the value of the independent variable of the $i^{\text {th }}$ data point

The prediction interval limits of R1 to R15 were converted into Gaussian uncertainty distributions, with mean $\hat{y}$ and standard deviation $\sigma$, by inserting Eq. (1) into the formula for the standard normal random variable, Z, given in Eq. (2), also adapted from Montgomery and Runger (2003). For a 95\% confidence prediction interval limit, $\alpha$ has to equal $5 \%$. The cumulative probability at $t_{\alpha / 2, v}$ therefore has to be $97.5 \%$ at which $Z$ equals 1.96.

$$
Z=\frac{Y-\hat{y}}{\sigma} \Rightarrow \sigma=\frac{Y-\hat{y}}{Z}=\frac{t_{\alpha / 2, v} \sqrt{\hat{\sigma}^{2}\left[1+\frac{1}{n}+\frac{(x-\bar{x})^{2}}{S_{x x}}\right]}}{1.96}
$$

\subsection{Results and discussion}

The scaling rules created can predict the total operation times of the five blisk designs within $4 \%$, using the expected values of the triangular distributions and the mean of the prediction intervals. This level of accuracy 
is not surprising, however, considering that the scaling rules are based on these operation times. Hence, this value only reflects the lack of fit of the regression lines. In order to validate the scaling rules, the operation times of a new blisk design were forecasted and the prediction was within $2.7 \%$ of the expectation of the manufacturing engineers.

\subsubsection{Unit cost prediction}

Figs. 14 and 15 display the scalable cost model's unit cost uncertainty distribution of a complex blisk with many features and a simple blisk with fewer features, respectively. Both figures, normalised with respect to the complex blisk's mean unit cost, also show a table that summarises statistical information related to the corresponding PDF and CDF graphs. As the error of the Monte Carlo Simulation is inversely proportional to the square root of the sample number, 100,000 samples were generated for each cost distribution in order to maximise the accuracy of the results. Despite the large uncertainty distribution of some of the scaling rules, including the one shown in Fig. 12, their impact is not significant considering that the 5th and 95th percentiles are within $8 \%$ and $13 \%$ of the complex and the simple blisk's average unit cost, respectively.

$\begin{gathered}\text { Complex Blisk Assembly Unit Cost } \\
\text { Distribution Summary }\end{gathered}$
\begin{tabular}{|l|r|}
\hline \multicolumn{1}{|c|}{ Measure } & Blisk Assembly Unit Cost \\
\hline Observations & 100,000 \\
\hline Mean & 1 \\
\hline Standard Deviation & 0.05 \\
\hline Posterior STD & $1.5 \mathrm{e}-4$ \\
\hline Variance & $2.2 \mathrm{e}-3$ \\
\hline Minimum & 0.81 \\
\hline 5th Percentile & 0.92 \\
\hline Median & 1 \\
\hline 95th Percentile & 1.08 \\
\hline Maximum & 1.18 \\
\hline
\end{tabular}

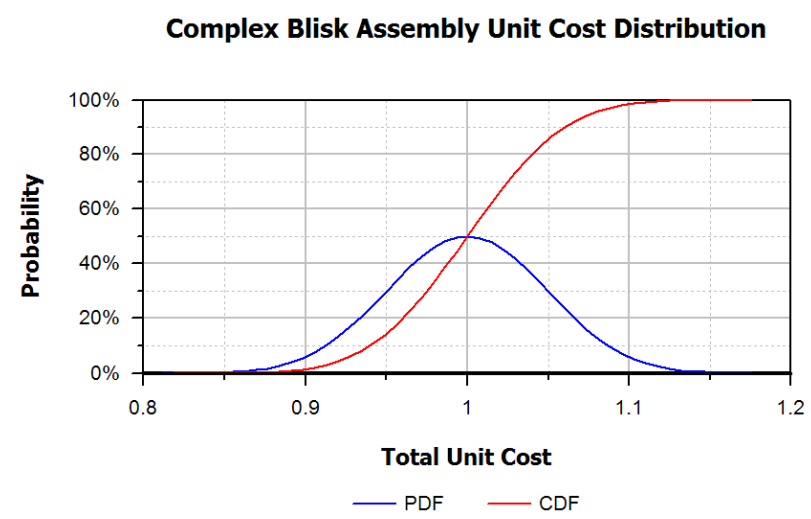

Fig. 14. Unit cost uncertainty distribution of the complex blisk.

Simple Blisk Assembly Unit Cost Distribution Summary

\begin{tabular}{|l|r|}
\hline \multicolumn{1}{|c|}{ Measure } & Blisk Assembly Unit Cost \\
\hline Observations & 100,000 \\
\hline Mean & 0.4 \\
\hline Standard Deviation & 0.03 \\
\hline Posterior STD & $9.7 \mathrm{e}-5$ \\
\hline Variance & $9.3 \mathrm{e}-4$ \\
\hline Minimum & 0.27 \\
\hline 5th Percentile & 0.35 \\
\hline Median & 0.4 \\
\hline 95th Percentile & 0.45 \\
\hline Maximum & 0.53 \\
\hline
\end{tabular}

Simple Blisk Assembly Unit Cost Distribution

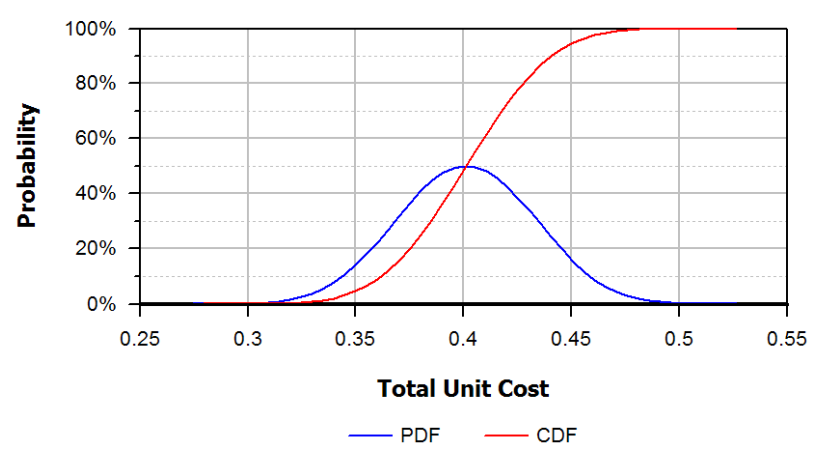

Fig. 15. Unit cost uncertainty distribution of the simple blisk.

Figs. 16 and 17 provide information at feature level based on the 14 sub-operations listed in Fig. 9. Although the scalable cost model cannot show all the bar charts simultaneously, the purpose of Figs. 16 and 17 is to highlight how much insight an activity-based-parametric hybrid can provide about how the resource consumption varies, depending on the design. 


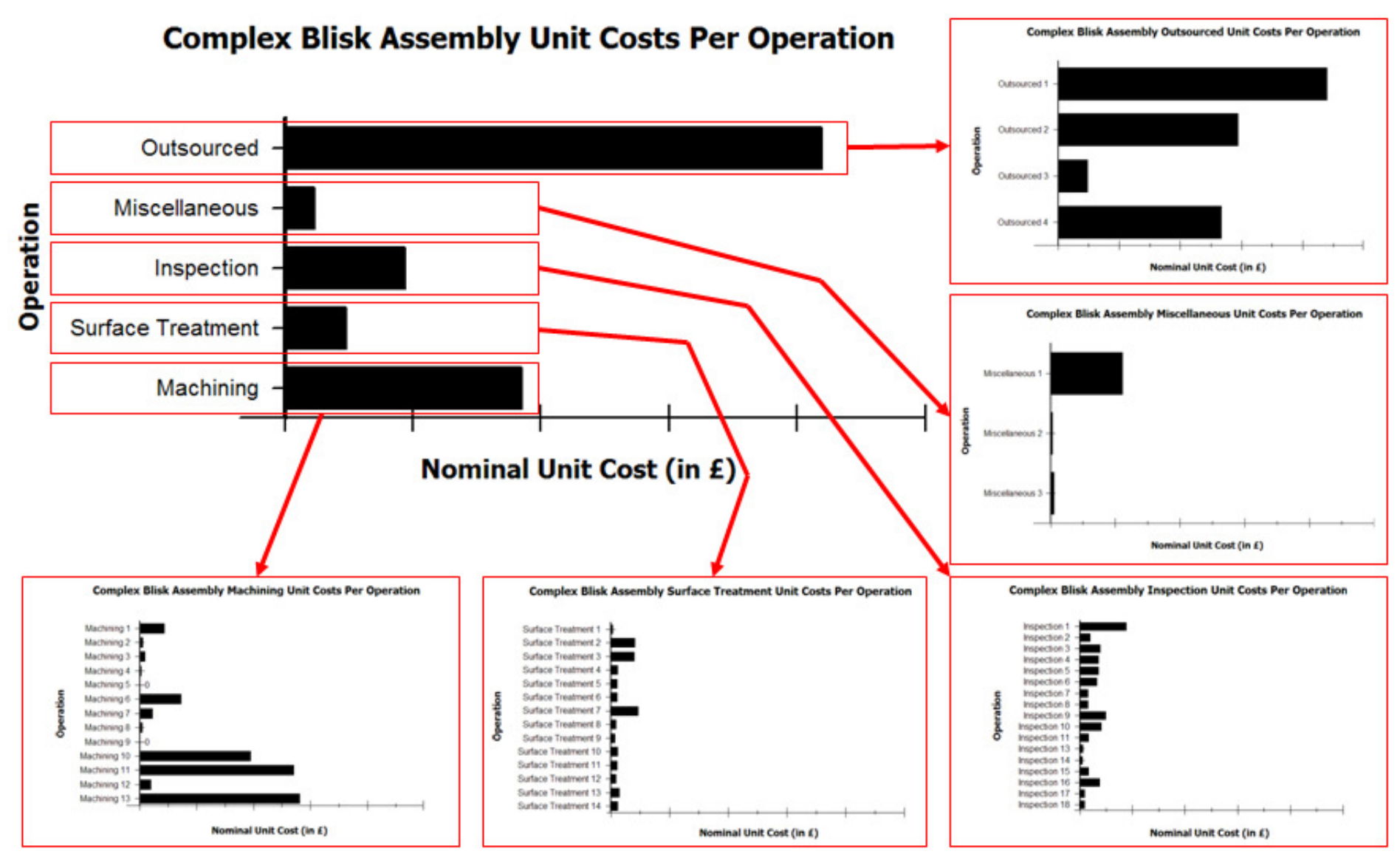

Fig. 16. Operation and feature unit costs of the complex blisk.

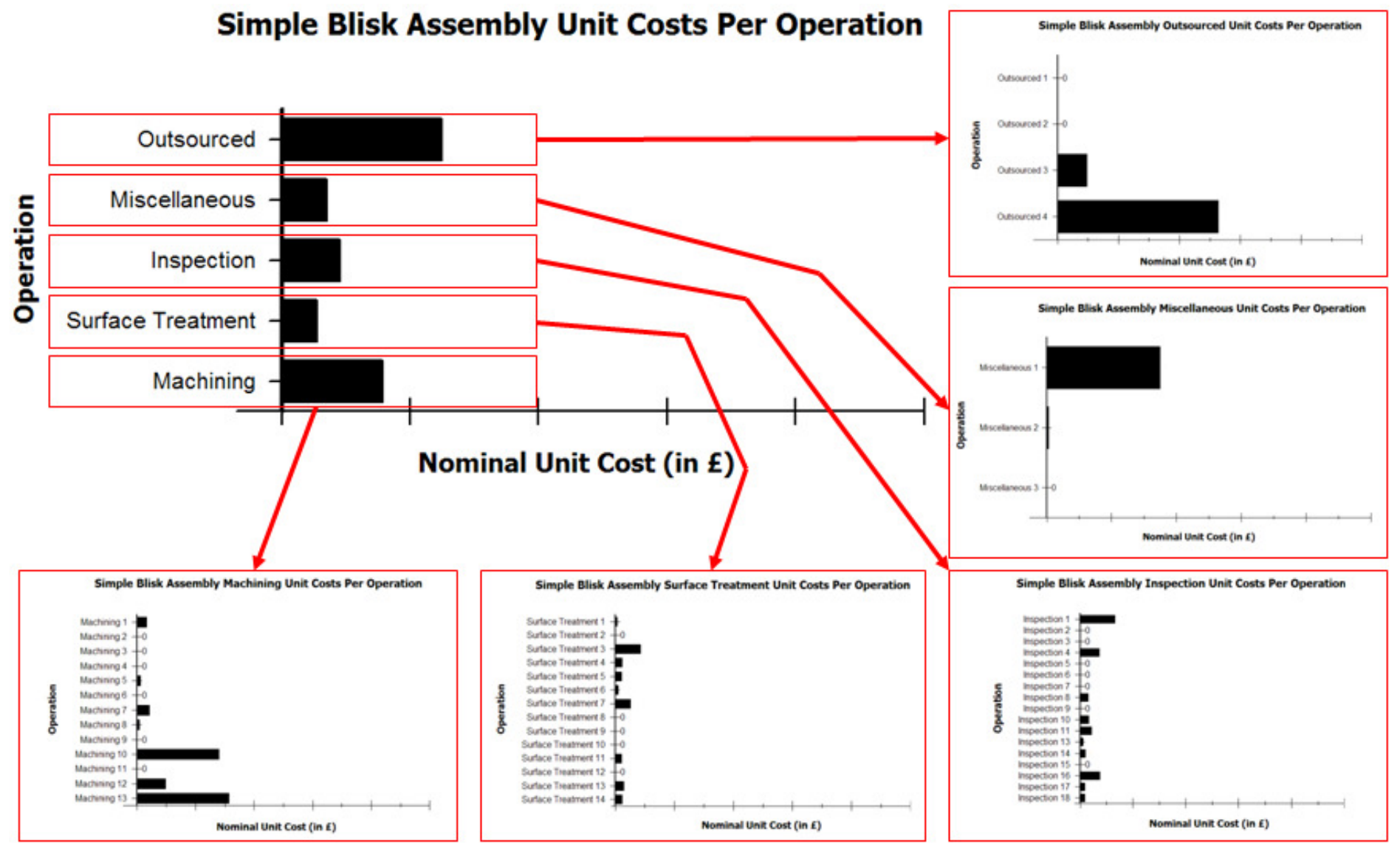

Fig. 17. Operation and feature unit costs of the simple blisk. 


\subsubsection{Blisk design space}

In order to explore how the blisk design parameters affect unit cost, a sensitivity study was carried out. This was done by generating a Design of Experiments (DoE) in Design-Expert ${ }^{\circledR}$, a commercial DoE program. In these computational experiments the number of blades, the root and the average blade stagger angle rates (i.e. the rate at which the blade twists at its root and over its entire length, respectively), the disc rim diameter and the disc surface area were varied independently over the ranges recorded for the five blisks. The blisk design data indicated that the number of blades and the blade surface area had a Pearson correlation coefficient of -0.917 , meaning that the blades got smaller as the number of blades increased. Throughout the DoE study, the number of blades therefore controlled the blade height and chord length accordingly. The remaining design parameters, such as the number of holes and seals, were first set at the complex blisk's and then the simple blisk's values, in order to plot a Pareto Chart and a response surface for both types as shown in Figs. 18 and 19, respectively.
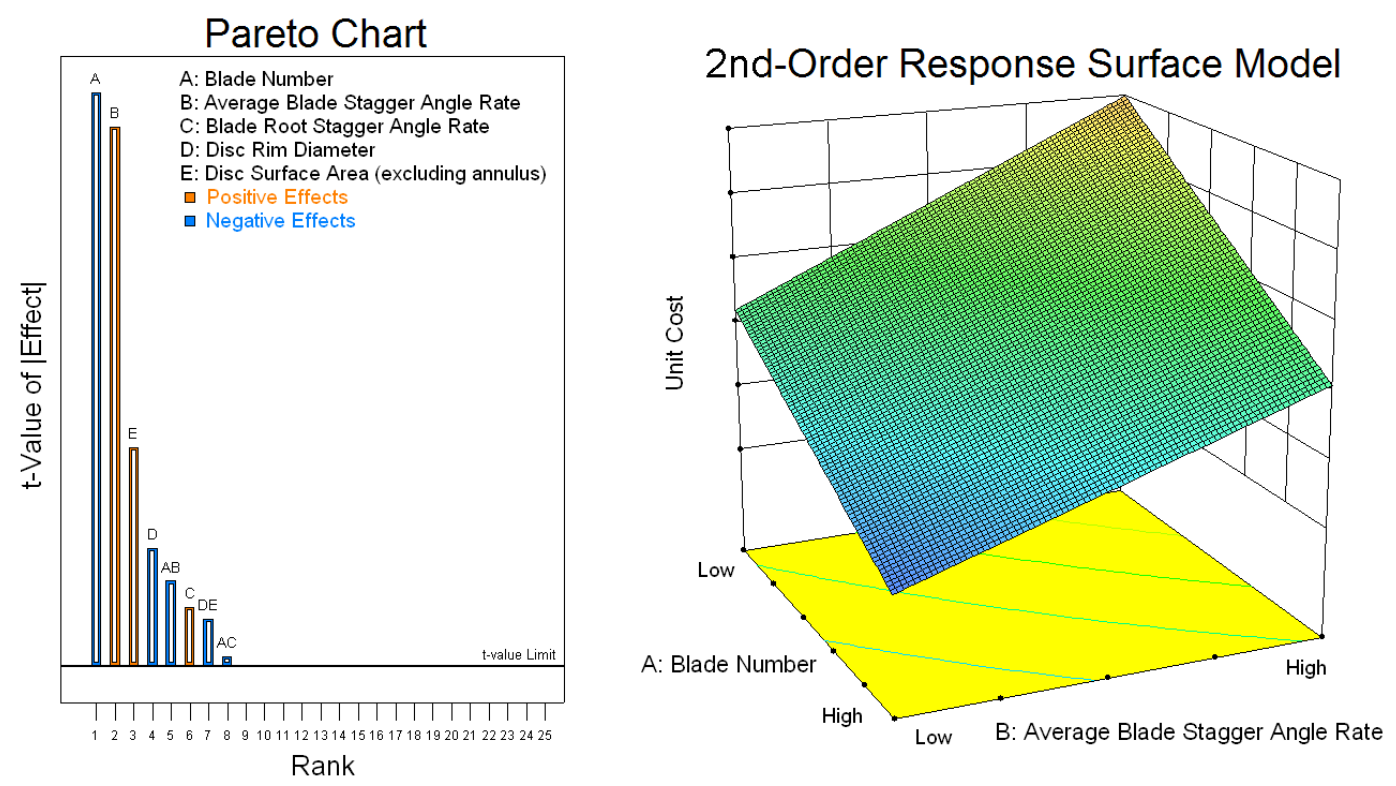

Fig. 18. Unit cost sensitivity of the complex blisk.
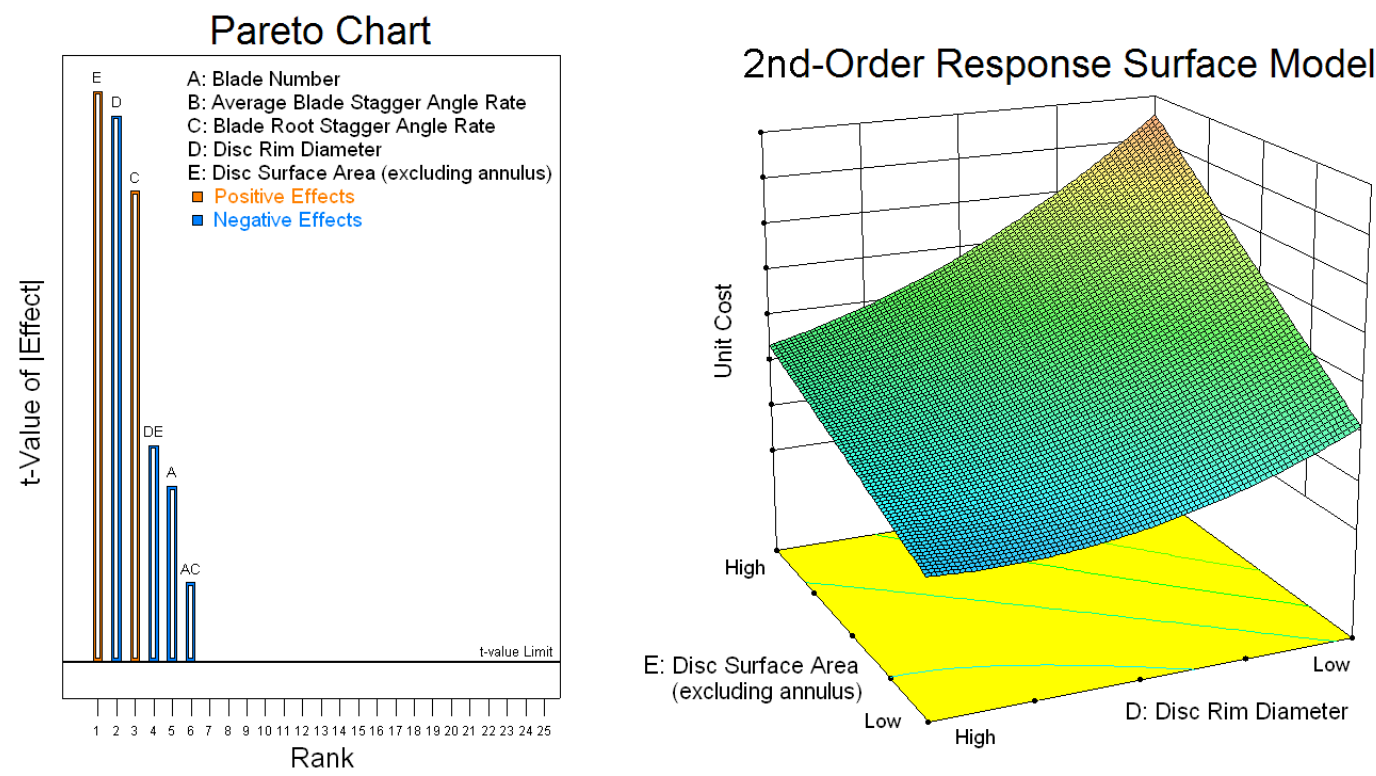

Fig. 19. Unit cost sensitivity of the simple blisk. 
The advantage of using Design Expert instead of conducting experiments randomly is that the software minimises the number of experiments required while also minimising statistical error. For this study that meant that Design Expert only needed 61 'design-optimally' distributed points in order to generate a third order surrogate model for the complex blisk. As the Pareto Chart in Fig. 18 indicates that the number of blades and the average blade stagger angle rate are the biggest cost drivers, the unit cost response surface of the complex blisk was plotted against those two parameters, while the remaining three cost drivers were set at their mean. Although the DoE is capable of detecting third order effects, the response surface is only second order because the Pareto Chart shows that only first order effects (like the blade number) and second order interaction effects (between the disc rim diameter and the disc surface area for example) are above the 5\% significance threshold labelled "t-value Limit". No insignificant effects are shown in the Pareto Chart because Design Expert removes these automatically. Since the scalable cost model has no discontinuities, the response surface has a $R^{2}$ value of $99.6 \%$ for the 61 design-optimally distributed points. Considering that unit cost increases as the number of blades is reduced means that the cost saving from the lower blade count does not compensate for the cost increase from the larger blades.

Unlike its counterpart, the Pareto Chart in Fig. 19 shows that the biggest cost drivers of the simple blisk are the disc surface area and the disc rim diameter, while the average blade stagger angle rate has no impact at all. These large changes can be explained by the fact that the simple blisk uses fewer and different scaling rules that do not depend on the average blade stagger angle rate. As the response surface therefore only had to model the variation of four design parameters, 40 instead of 61 design-optimally distributed points were needed in order to detect third order effects. Similar to Fig. 18, the Pareto Chart in Fig. 19 shows that only first and second order effects are significant. Just like before, a second order response surface was therefore plotted against the two biggest cost drivers, while the other two parameters were set at their mean. Although it makes sense that unit cost increases with disc surface area, it might seem counterintuitive that cost decreases with an increasing disc rim diameter. The explanation is that for a given disc surface area, a smaller rim diameter will increase the cross-sectional perimeter of the disc. As a blisk with a large perimeter tends to have more expensive features, a smaller rim diameter leads to a higher unit cost unless the disc surface area reduces proportionately.

\section{Conclusion and recommendations}

\subsection{Factory cost model}

The factory cost model can aid manufacturing engineers optimise their methods of manufacture by indicating how cost can be minimised while meeting the required throughput and quality. Manufacturing costs can be reduced, for example, by trading inspection costs between machining operations against potential scrap costs resulting from removing these inspections (Marsh et al., 2007). If the model is loaded onto a global server, the latest methods of manufacture, operation times and cost estimates can also be viewed and updated by the rest of the organisation through Vanguard Studio's standard web browser, facilitating design automation and the integration of cost into design optimisation frameworks (Scanlan et al., 2006).

While the factory cost model was being built, R-R created a factory simulation for the future LFW blisk factory in WITNESS ${ }^{\circledR}$, a commercial simulation package. Unlike the factory cost model, a factory simulation can model the stochastic nature of manufacturing that arises due to the dynamic effect of time (Spedding and Sun, 1999). As an event in a simulation occurs at the same level as an activity in an ABC model, the factory simulation 
should be linked to the factory cost model to enable ABC to move beyond the static framework (Spedding and Sun, 1999; Von Beck and Nowak, 2000). Finally, the creation of the factory cost model's manufacturing cell files should be fully automated and the factory model adjusted so that uncertainty ranges can be applied to the inputs. This would enable the uncertainty in the operation times, calculated by the scalable blisk cost model or the WITNESS factory simulation for example, to be taken into account.

\subsection{Scalable blisk cost model}

Using the scalable cost model in conjunction with the factory cost model offers a step towards implementing Toyota's Set-Based Concurrent Engineering (SBCE) principles, where design engineering and manufacturing engineering define a large set of feasible design solutions from their respective areas of expertise and, through an interactive process, gradually converge on a final design (Sobek et al., 1999). Unlike traditional design practice, SBCE does not fix the final design early in the design process, resulting in a reduced risk of both time-consuming rework and sub-optimal product performance (Sobek et al., 1999). As it is difficult to explain why a particular combination of design parameters produced the best fit for the regressed scaling rules, it is not advisable to use the scalable cost model in optimisation routines without further validation. A sensitivity study such as the one in Section 4.5 .2 can be beneficial, however, because it highlights the biggest cost drivers and how they affect cost. Such a study also allows the engineers to assess whether the cost model is realistic.

Since Vanguard Studio can handle cumulative uncertainty distributions, ideally, the user should have the option of attributing uncertainty ranges to the inputs of the scalable cost model in addition to the uncertainty distributions that already exist for the scaling rules. In view of the fact that the LFW blisk operation times are likely to change as the processes mature and, with time, further blisk designs will be created, the scaling rules should be updated and validated at regular intervals. These updates could also help improve the scaling rule shown in Fig. 12.

\section{Role of the funding source}

This project is sponsored by Rolls-Royce plc, a power systems provider, and the United Kingdom's Engineering and Physical Sciences Research Council (EPSRC). Rolls-Royce also supplied the data that was used to build the cost models and ensured that no confidential information is published in this paper.

\section{Acknowledgements}

The authors are very grateful for the contributions many Rolls-Royce employees have made to this paper, including Simon Muschamp, Weiliang Lou, Andrew Tudge, David Reuss and Michael Rushe. Without their help the authors would not have been able to collect the required data and build the cost models presented in this paper.

\section{References}

Bearden, D.A., 2001. Small-satellite costs. Crosslink, 2 (1), 32-44.

Birkler, J.L., Garfinkle, J.B., Marks, K.E., 1982. Development and production cost estimating relationships for aircraft turbine engines. RAND Corporation. <http://www.rand.org/pubs/notes/2005/N1882.pdf>.

Book, S.A., 2001. Estimating probable system cost. Crosslink, 2 (1), 12-21. 
Bussmann, M., Bayer, E., 2009. Blisk production of the future - technological and logistical aspects of futureoriented construction and manufacturing processes of integrally bladed rotors. In: Proceedings of the 19th International Symposium on Air Breathing Engines (ISABE), Montreal, Canada.

Bussmann, M., Kraus, J., Bayer, E., 2005. An integrated cost-effective approach to blisk manufacturing. In: Proceedings of the 17th International Symposium on Air Breathing Engines (ISABE), Munich, Germany. Chan, Y.J., 2009. Variability of Blade Vibration in Mistuned Bladed Discs. Ph.D. Thesis, Imperial College London, United Kingdom.

Collopy, P., Curran, R., 2005. The challenge of modeling cost: the problem. In: Proceedings of the 1st International Conference on Innovation and Integration in Aerospace Sciences, Belfast, United Kingdom. Collopy, P.D., Eames, D.J.H., 2001. Aerospace manufacturing cost prediction from a measure of part definition information. In: Proceedings of the SAE World Aviation Congress and Exposition, Seattle, USA. Cooper, R., Kaplan, R.S., 1987. How cost accounting systematically distorts product costs. In: Bruns, W.J., Kaplan, R.S., (Eds.), Accounting and management: field study perspectives. Harvard Business School, 204228.

Cooper, R., Kaplan, R.S., 1991. Profit priorities from activity-based costing. Harvard Business Review, 69 (3), 130-135.

Coppinger, R., 2008. MTU Aero Engines claims blisk repair first. Flightglobal.

Curran, R., Kundu, A.K., Wright, J.M., Crosby, S., Price, M., Raghunathan, S., Benard, E., 2006. Modelling of aircraft manufacturing cost at the concept stage. International Journal of Advanced Manufacturing Technology, 31 (3), 407-420.

Curran, R., Price, M., Raghunathan, S., Benard, E., Crosby, S., Castagne, S., Mawhinney, P., 2005. Integrating aircraft cost modeling into conceptual design. Concurrent Engineering, 13 (4), 321-330.

Curran, R., Raghunathan, S., Price, M., 2004. Review of aerospace engineering cost modelling: the genetic causal approach. Progress in Aerospace Sciences, 40 (8), 487-534.

Dryden, J.A., Large, J.P., 1977. A critique of spacecraft cost models. RAND Corporation.

<http://www.rand.org/pubs/reports/2006/R2196-1.pdf>.

Finnie, G.R., Wittig, G.E., Desharnais, J.M., 1997. A comparison of software effort estimation techniques: using function points with neural networks, case-based reasoning and regression models. Journal of Systems and Software, 39 (3), 281-289.

Ford, S., Tao, L., Probert, D., 2008. Preparing for takeoff: breakthrough process innovation at Rolls-Royce. In: Proceedings of the Portland International Conference on Management of Engineering and Technology (PICMET) 2008, Cape Town, South Africa, 629-638.

Kim, G.H., An, S.H., Kang, K.I., 2004. Comparison of construction cost estimating models based on regression analysis, neural networks, and case-based reasoning. Building and Environment, 39 (10), 1235-1242.

Kosing, O.E., Scharl, R., Schmuhl, H.J., 2001. Design improvements of the EJ200 HP compressor - from design verification engine to a future all blisk version. In: Proceedings of the ASME Turbo Expo 2001: Land, Sea, and Air, New Orleans, USA.

Kwak, Y.H., Watson, R.J., 2005. Conceptual estimating tool for technology-driven projects: exploring parametric estimating technique. Technovation, 25 (12), 1430-1436. 
Marsh, R., Cheung, W.M., Lanham, J., Newnes, L., Mileham, A., 2007. Modelling an assembly process using a close coupled generative cost model and a discrete event simulation. In: Proceedings of the 4th International Conference on Digital Enterprise Technology, Bath, United Kingdom, 339-346.

Minitab, 2007. Minitab 15 Help. Minitab Inc.

Montgomery, D.C., Runger, G.C., 2003. Applied Statistics and Probability for Engineers, 3rd ed. John Wiley \& Sons.

Muia, T., Salam, A., Bhuiyan, N.F., 2009. A comparative study to estimate costs at Bombarier Aerospace using regression analysis. In: Proceedings of the IEEE International Conference on Industrial Engineering and Engineering Management, Hong Kong, China, 1381-1385.

Qian, L., Ben-Arieh, D., 2008. Parametric cost estimation based on activity-based costing: a case study for design and development of rotational parts. International Journal of Production Economics, 113 (2), 805-818. Rolls-Royce, 2005. The Jet Engine, 6th ed. Rolls-Royce plc. <http://www.rollsroyce.com/about/publications/jet_engine_book/>.

Scanlan, J., Hill, T., Marsh, R., Bru, C., Dunkley, M., Cleevely, P., 2002. Cost modelling for aircraft design optimization. Journal of Engineering Design, 13 (3), 261-269.

Scanlan, J., Rao, A., Bru, C., Hale, P., Marsh, R., 2006. DATUM project: cost estimating environment for support of aerospace design decision making. Journal of Aircraft, 43 (4), 1022-1028.

Smith, A.E., Mason, A.K., 1997. Cost estimation predictive modeling: regression versus neural network. The Engineering Economist, 42 (2), 137-161.

Sobek, D.K., Ward, A.C., Liker, J.K., 1999. Toyota's principles of set-based concurrent engineering. Sloan Management Review, 40 (2), 67-83.

Spedding, T.A., Sun, G.Q., 1999. Application of discrete event simulation to the activity based costing of manufacturing systems. International Journal of Production Economics, 58 (3), 289-301.

Stat-Ease, 2010. Stat-Ease Help. Design-Expert 8.0.4. Stat-Ease Inc.

Steffens, K., 2001. Advanced compressor technology - key success factor for competitiveness in modern aero engines. In: Proceedings of the 15th International Symposium on Air Breathing Engines (ISABE), Bangalore, India.

Takakuwa, S., 1997. The use of simulation in activity-based costing for flexible manufacturing systems. In: Proceedings of the 1997 Winter Simulation Conference, Atlanta, USA, 793-800.

Vanguard, 2010. Monte Carlo Simulation Add-In. Vanguard Software Corp.

Von Beck, U., Nowak, J.W., 2000. The merger of discrete event simulation with activity based costing for cost estimation in manufacturing environments. In: Proceedings of the 2000 Winter Simulation Conference, Orlando, USA, 2048-2054.

Xu, J.J., 2006. Combining Activity-Based Costing with Manufacturing Simulation. M.Sc. Thesis, Cranfield University, United Kingdom.

Younossi, O., Arena, M.V., Moore, R.M., Lorell, M., Mason, J., Graser, J.C., 2003. Military jet engine acquisition - technology basics and cost-estimating methodology. RAND Corporation.

<http://www.rand.org/content/dam/rand/pubs/monograph_reports/2005/MR1596.pdf>.

Zhan, H., Zhao, W., Wang, G., 2000. Manufacturing turbine blisks. Aircraft Engineering and Aerospace

Technology, 72 (3), 247-252. 